\title{
Numerical analysis of an intense rainstorm occurred in southern Italy
}

\author{
S. Federico ${ }^{1,2}$, E. Avolio ${ }^{2,3}$, C. Bellecci ${ }^{2,3}$, A. Lavagnini ${ }^{4}$, M. Colacino ${ }^{4}$, and R. L. Walko ${ }^{5}$ \\ ${ }^{1}$ CNR-ISAC, Strada Prov. Lecce-Monteroni km 1.2, Lecce, Italy \\ ${ }^{2}$ CRATI Scrl, c/o Università della Calabria, Rende (CS), Italy \\ ${ }^{3}$ Facoltà di Ingegneria-Università di "Tor Vergata", via del Politecnico 1, Rome, Italy \\ ${ }^{4}$ CNR-ISAC, Via del Fosso del Cavaliere 100, Rome, Italy \\ ${ }^{5}$ Pratt School, Duke University, Durham, NC, USA
}

Received: 11 May 2007 - Revised: 24 September 2007 - Accepted: 5 December 2007 - Published: 11 January 2008

\begin{abstract}
In this study we conduct a numerical analysis of an intense and destructive storm that occurred over Calabria, southern Italy, on 10-12 December 2003. More than $250 \mathrm{~mm}$ of precipitation was recorded over a large area in southern Calabria and one station reported about $660 \mathrm{~mm}$ in two days (more than half of the yearly climatological value). Precipitation fell mainly during 11 and 12 December. The storm was characterized by the entrance of an Atlantic upper-level trough associated with a deep surface low that advected humid marine air toward steep Calabrian orography. The steep mountain ridges favoured landslides, which were reported in several villages. Property damage was extensive.

We study the storm at the mesoscale by means of the Regional Atmospheric Modeling System (RAMS). The model was successful at representing the observed accumulated rainfall patterns. This justifies our use of RAMS for further analysis of the physical and dynamic factors involved in the storm event. In particular, we use RAMS to evaluate the roles of Calabrian orography, surface latent heat flux, and upper level forcing.

The key role of a potential vorticity (PV) streamer, which forced the entire meteorological system from the upper levels is assessed by the PV inversion technique in a Limited Area Model Ensemble Prediction System (LEPS) framework.

Results show that the roles of Calabrian orography and surface latent heat flux are important in our simulations. Indeed, humid marine air masses were advected by the synoptic flow toward Calabrian steep coastal mountain ranges determining intense and abundant rainfall.
\end{abstract}

Correspondence to: S. Federico

(s.federico@isac.cnr.it)

\section{Introduction}

The Mediterranean region is characterized by torrential rainfall and flash floods at different spatial and temporal scales (Siccardi, 1996; Jansa, 1994). Several events have been studied, discussed, and reported in various countries around the Mediterranean basin (Homar et al., 2001; Fehlman et al., 2000; Buzzi and Foschini, 2000; Alpert et al., 2002).

From the meteorological perspective, atmospheric forcing spans different spatial and temporal scales and determines different types of intense rainfall in the Mediterranean region.

The most common type of intense cyclone in the Mediterranean region is the baroclinic lee cyclone of the type described in Buzzi and Tibaldi (1978). These cyclones can be quite intense over Calabria (Fig. 1), where our study is focused. The peculiar geographical features of Calabria, i.e. the presence of steep mountain ranges near a warm sea, can lead to persistent precipitation patterns over localized areas (Federico et al., 2003a).

In some cases, intense localized cyclones at the subsynoptic scale were the cause of major events, such as the Mediterranean Hurricane (Medicane) of 4-6 October 1996 reported by Atlas and Reale (2001), or the Crotone supercell-like storm studied by Federico et al. (2003b). There are several other cases in which heavy precipitation in the Mediterranean occurred without a clear deep cyclone development and the synoptic scale features resembled cases in which little rain was observed. Recent studies (Krichack et al., 2004; Turato et al., 2004) suggest that for these major floods events, moisture sources were outside the Mediterranean basin and large-scale water vapour transport was important.

Published by Copernicus Publications on behalf of the European Geosciences Union. 


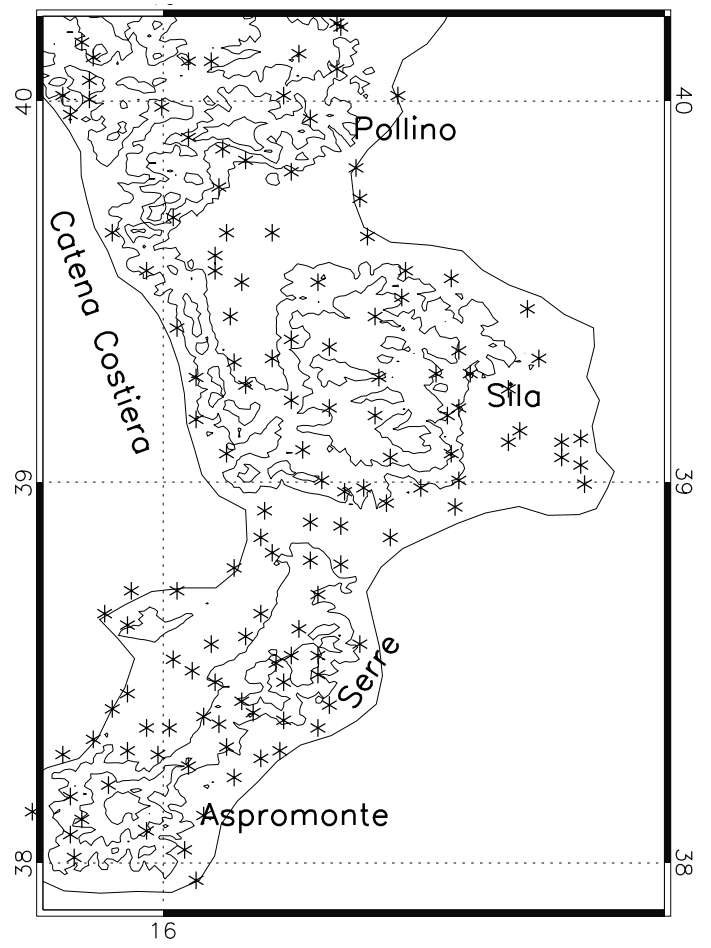

Fig. 1. Topography of Calabria peninsula with main mountain ranges names. Contours are for 500, 1000 and $1500 \mathrm{~m}$ elevation. Asterisks are rain gauge locations.

In the extra-tropical atmosphere intense cyclones often develop under upper-tropospheric jet streams that are often characterized by anomalously high values of potential vorticity (PV). PV is conserved along the flow on a isentropic surface under adiabatic and frictionless motion (Hoskins et al., 1985). Because of its conservative property, PV is used to trace areas with specific air mass characteristics and is applied in the analysis of atmospheric processes. The positive PV anomalies influence the timing, amplitude, and location of intense surface cyclones and heavy precipitation events by upper level forcing (Fehlman and Davies, 1999; Krichack et al., 2007). Accurate specification of the troposphere PV distribution might be necessary for the successful prediction of hazardous weather events (Romero et al., 2005).

Unusually intense rainfall occurred on 10-12 December 2003 over Calabria, southern Italy. Figure 2 shows the accumulated precipitation from 00:00 UTC 10 December 2003 to 00:00 UTC 13 December 2003 objectively analyzed by a Cressman-type scheme with $0.15 \circ$ search radius, which smears the $660 \mathrm{~mm}$ maximum measured value. During the entire storm event, the flow was mainly from the southeast and there was a partial shielding effect from the mountain ranges that led to more precipitation over the Ionian coastal areas. Moreover, accumulated rain was greater over the main peaks (Sila, Serre and Aspromonte) due to orographic uplift. Because of the high precipitation values that were recorded,

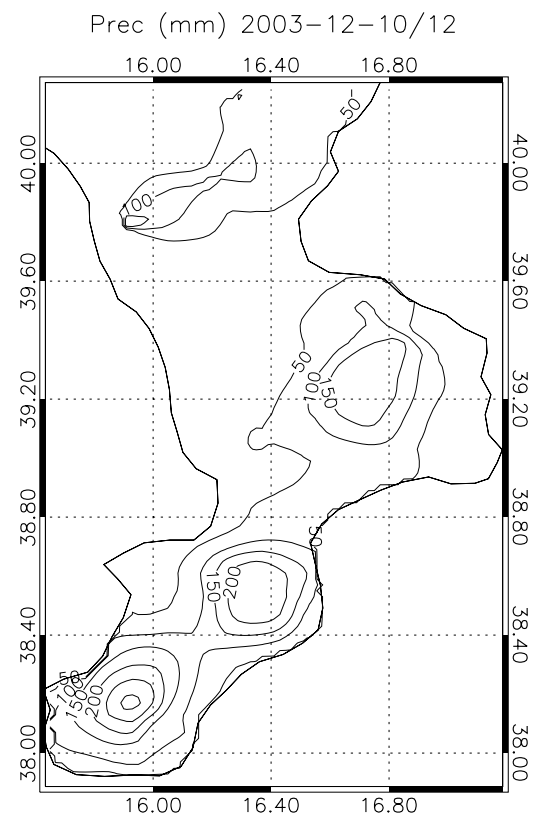

Fig. 2. Total precipitation $(\mathrm{mm})$ objectively analyzed for the entire event. Contours from $50 \mathrm{~mm}$ to $300 \mathrm{~mm}$ every $50 \mathrm{~mm}$.

this storm is a prototype for intense rainfall events over Calabria and can help to determine key factors involved in such events, both at the synoptic scale and mesoscale.

The purpose our study is to assess the roles of one boundary (orography), one physical (surface latent heat flux), and one dynamic factor (upper level PV anomaly) for this storm event.

Orography and latent heat flux are expected to be important factors because throughout the event the synoptic flow in the lower troposphere was mainly from the southeast and advected humid and relatively warm air masses toward the steep Calabrian orography. The anomalously high PV values of this cyclone modified the atmospheric stratification and forced vertical motions, which is expected to be important for atmospheric development in our simulations.

This paper is organized as follows: in Sect. 2 we present available observations from the regional rain gauge network and give a synoptic overview of the storm event, in Sect. 3 we describe the model set up and the simulation strategy, and in Sect. 4 we report and discuss the results. Conclusions are given in Sect. 5.

\section{Rain gauge observations and synoptic overview}

In this study we are interested in the precipitation field and the mesoscale processes involved, thus we evaluate model performance by comparing model precipitation output with 


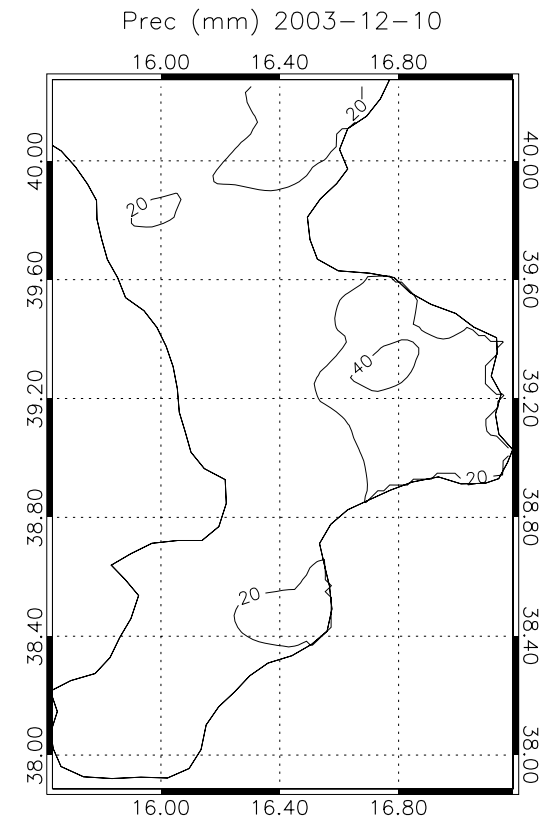

Fig. 3a. Total precipitation (mm) for 10 December 2003. Contours are for $20 \mathrm{~mm}$ and $40 \mathrm{~mm}$.

the recorded rainfall from the regional rain gauge network. This analysis is made on a daily basis.

Figure $3 \mathrm{a}, \mathrm{b}$, and c shows the total precipitation accumulated for 10, 11 and 12 December 2003, respectively, analyzed by the Cressman objective scheme. Recorded rainfall from more than 130 stations is available for our study.

Rainfall started during the second part of 10 December. From Fig. 3 it is evident that:

- Precipitation is greater for 11 and 12 December compared to 10 December;

- For 10 December rainfall is located upwind of the main peaks, and for 11 and 12 December an area of high precipitation occurred on the lee of Aspromonte where landslides were reported in several villages.

Figure 4a shows the low level ECMWF (European Centre for Medium-range Weather Forecast) operational analysis at 12:00 UTC 10 December 2003. A low pressure pattern is centred over Algeria and warm humid air masses are advected onto the Calabrian east coast. During the following $12 \mathrm{~h}$, intense rainfalls were reported in several villages of the Ionian coast.

Figure $4 \mathrm{~b}$ shows the upper level analysis for the same time as Fig. 4a. For the extra tropics, PV values greater than $3 \mathrm{PV}$ units (PVU) are inferred to represent stratospheric air masses because of the high values of static stability in this portion of the atmosphere. PV values of 1.5-3 PVU represent air that originated near the tropopause. PV values less

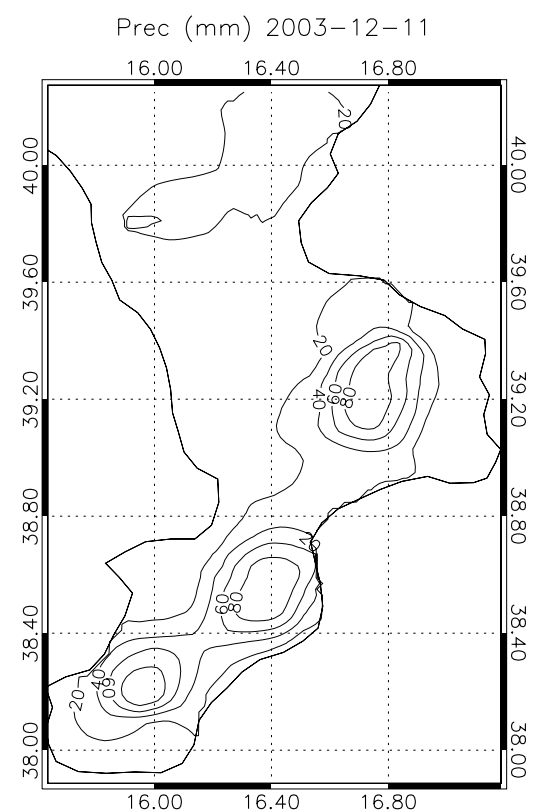

Fig. 3b. Total precipitation (mm) for 11 December 2003. Contours from $20 \mathrm{~mm}$ to $80 \mathrm{~mm}$ every $20 \mathrm{~mm}$.

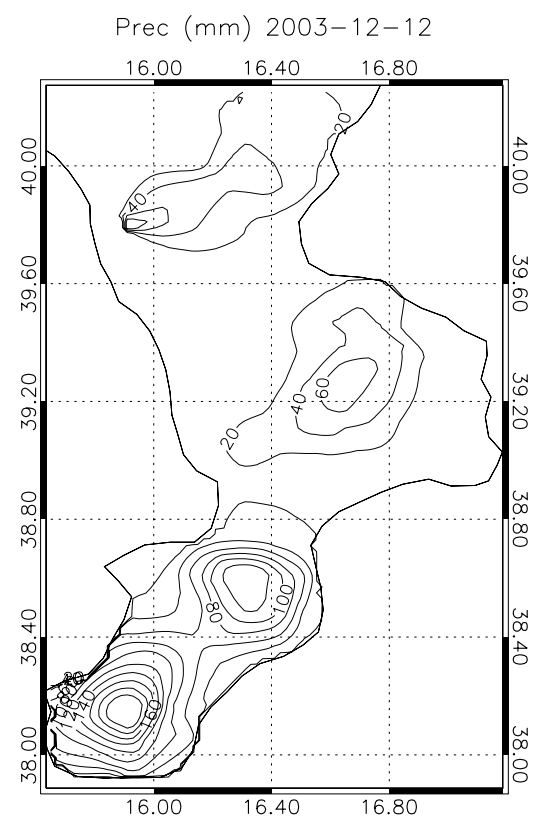

Fig. 3c. Total precipitation (mm) for 12 December 2003. Contours from $20 \mathrm{~mm}$ to $200 \mathrm{~mm}$ every $20 \mathrm{~mm}$.

than 1.5 PVU represent tropospheric air masses (Krichack et al., 2004). Positive PV anomalies are often found in areas with downward propagation of stratospheric air masses (Santurette and Georgiev, 2005) and, following the classification described above, the height of the 1.5 PVU surface is usually assumed as the height of the dynamic tropopause. 


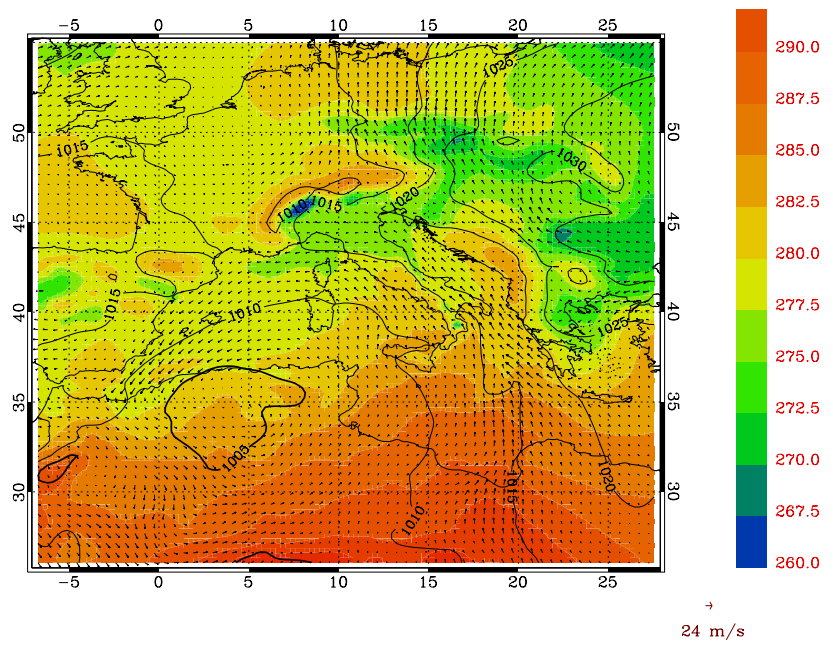

Fig. 4a. Sea level pressure (hPa, solid contours), $925 \mathrm{hPa}$ temperature (K, filled contours) and $925 \mathrm{hPa}$ winds. The map is valid on 12:00 UTC 10 December 2003.
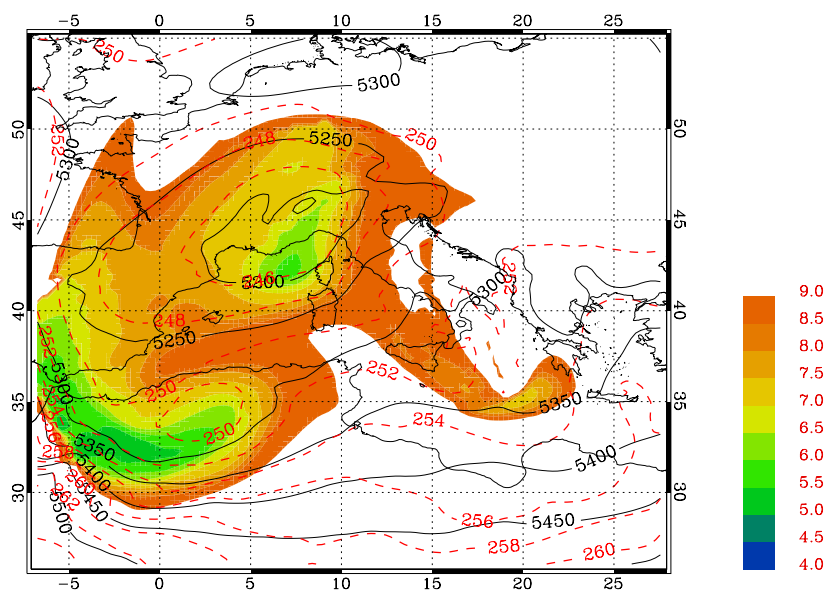

Fig. 4b. $500 \mathrm{hPa}$ geopotential height (m, solid contours), $500 \mathrm{hPa}$ temperature $(\mathrm{K}$, dashed contours) and 1.5 PVU surface height $(\mathrm{km}$, filled contours). The map is valid on 12:00 UTC 10 December 2003.

During the following day the sea level pressure cyclone moved eastward and the pressure minimum reached the Libyan coast at about 12:00 UTC 11 December. Then it moved northeastward crossing Calabria and Sicily. This evolution is well illustrated by Figs. 5a and $\mathrm{b}$.

Also well illustrated by Fig. 5b are the upper level cutoff associated with the surface low and the elongated tropospheric intrusion of stratospheric air masses located over Africa.

It is worth noting that winds over the Ionian Sea intensify throughout the cyclone evolution and advect moist air masses toward the Ionian coast. In addition, the height of the

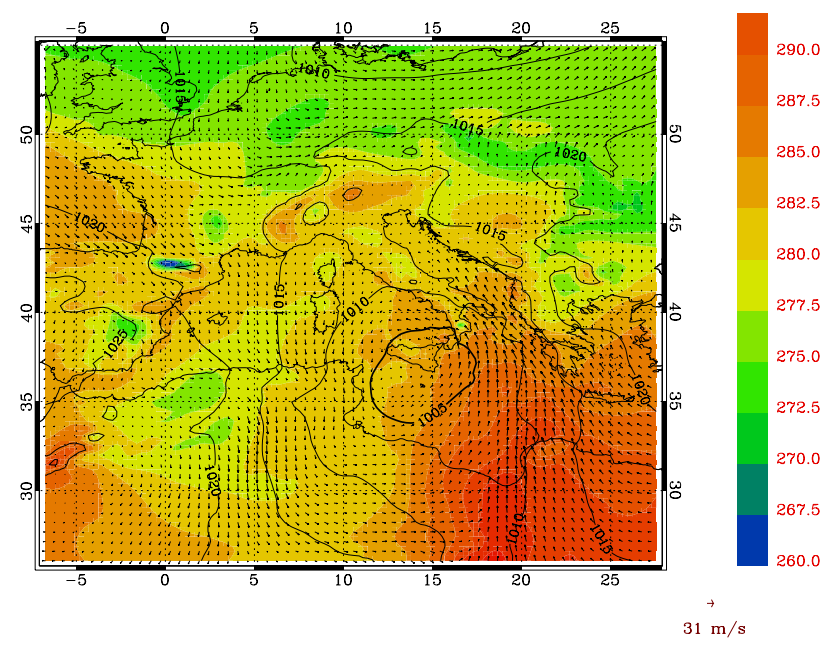

Fig. 5a. As in Fig. 4a on 00:00 UTC 12 December 2003.

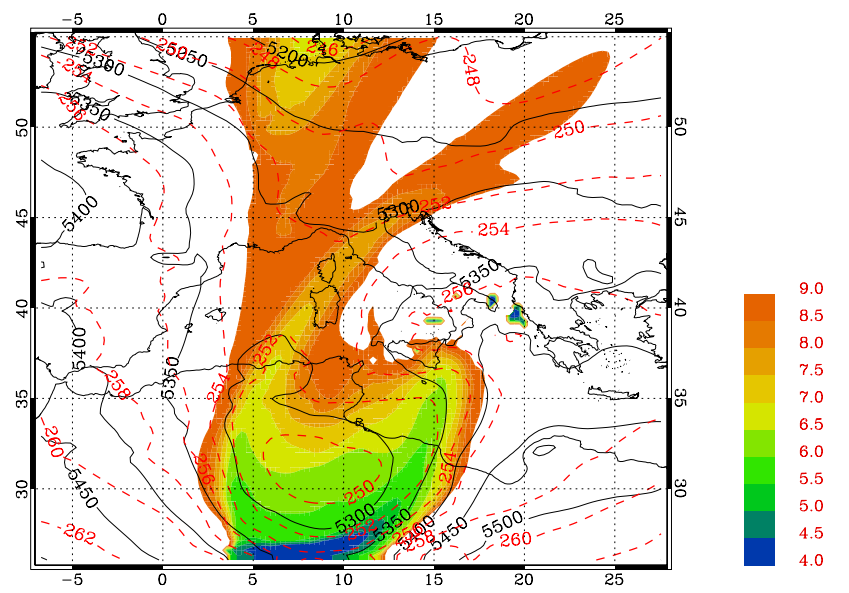

Fig. 5b. As in Fig. 4b on 00:00 UTC 12 December 2003.

1.5 PVU surface in Fig. 5b is lower than in Fig. 4b, and its minimum height is closer to the central Mediterranean basin. Likely, this meteorological situation determines a more direct upper level forcing of the circulation over the area.

\section{Model setup and numerical experiments}

The following is a brief description of the model set up including the options selected. For details on RAMS, the reader should refer to Pielke et al. (1992) and Cotton et al. (2003).

RAMS domains are shown in Fig. 6. Horizontal grid spacing is $30 \mathrm{~km}, 10 \mathrm{~km}$, and $3.3 \mathrm{~km}$ for the first, second, and third grid. Grid nesting uses a two way interactive procedure. Thirty vertical levels, up to $17000 \mathrm{~m}$ in the terrain following 
Table 1. Numerical analysis RAMS simulations.

\begin{tabular}{lll}
\hline Simulation & Physics & FF \\
\hline$f_{0}$ & Full physics & $f_{0}+f_{1}-\left(f_{2}+f_{3}\right)=$ combined effect \\
$\mathrm{f}_{1}$ & No Calabria orography, no surface latent heat flux & $/$ \\
$f_{2}$ & Calabria orography, no surface latent heat flux. & $f_{2}-f_{1}=$ role of calabrian orography \\
$f_{3}$ & No Calabria orography, surface latent heat flux. & $f_{3}-f_{1}=$ role of surface latent heat fluxes \\
$f_{4}$ & PV enhanced of 25\% of its value for a selected PV element. & $/$ \\
$f_{5}$ & PV reduced of 25\% of its value for a selected PV element. & $/$ \\
\hline
\end{tabular}

coordinate system, are used in the simulations. Levels are not equally spaced: Layers within the Planetary Boundary Layer (PBL) are between 50 and $200 \mathrm{~m}$ thick, whereas layers in the middle and upper troposphere are $1000 \mathrm{~m}$ thick.

Parameterization of the surface water and energy budgets and fluxes with the atmosphere are described in Walko et al. (2000).

Non-convective precipitation is computed from explicit prognostic equations for seven water categories: Cloud particles, rain, pristine ice, snow, aggregates, graupel, and hail. Convective precipitation is parameterized following Molinari and Corsetti (1985) who proposed a simplified form of the Kuo scheme that accounts for updrafts and downdrafts. Convective parameterization is applied to the first and second RAMS domains.

Six simulations, summarized in Table 1, are discussed and we divide them in two groups: The first group (four simulations), contains the control forecast and evaluates the role of one boundary factor (Calabrian orography) and one physical (surface latent heat flux), the second group (two simulations) shows the sensitivity of the case study to upper level forcing.

We expect that Calabrian orography and surface latent heat flux will be important in our simulations because the surface wind pattern is mainly from the southeast and advects relatively warm humid air masses toward the Calabrian mountain peaks. To study this issue, we adopt the methodology proposed by Stein and Alpert (1993) in order to isolate the role of each factor and their combined effect. When more than one factor is considered, it is not sufficient to compare a simulation done by removing some physical effect from the control simulation (in our study, simulation $f_{0}$ ) because the contribution associated with the interaction of two (or more) factors must be considered. A complete factor separation for $n$ factors requires $2^{n}$ simulations, and thus we perform 4 simulations. Table 1 lists the 4 simulations and the algebraic combinations used to isolate the effects of the two factors.

The second group of simulations aims to estimate the sensitivity of the case study to dynamic upper level forcing by the PV inversion technique in a Limited Area Model Ensemble Prediction System (LEPS) framework. The ensemble setup is chosen for three main reasons. First, LEPS gives different scenarios compatible with the analysis/forecast errors and their comparison is a powerful tool to gain insight into

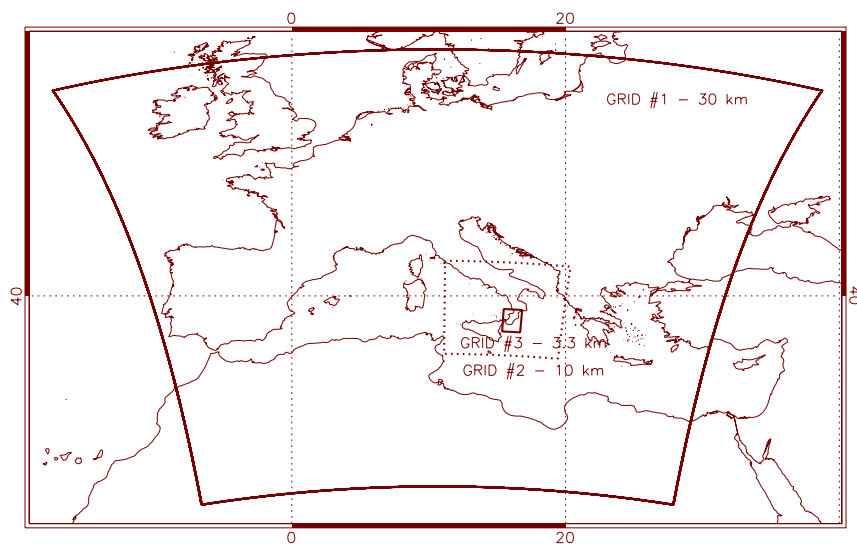

Fig. 6. RAMS domains.

the physical behaviour of the meteorological system. Moreover, in our methodology, scenarios are generated by maximizing the differences in the upper level PV anomaly and their comparison shows indirectly the scenarios sensitivity to the upper level PV anomaly. Second, the modelled pseudo water vapour images can be compared with the corresponding METEOSAT water vapour scene for different scenarios to evaluate their reliability (Santurette and Georgiev, 2005; Federico et al., 2007), adding value to the forecast. Third, the methodology presented can be easily implemented operationally.

Initial and dynamic boundary conditions for the first group of simulations are derived from the ECMWF 12:00 UTC 9 December 2003 operational deterministic analysis/forecast cycle. Initial and dynamic boundary conditions for the second group are derived from the ECMWF-EPS (Ensemble Prediction System) operational cycle of the 12:00 UTC 9 December 2003.

All simulations, except for the PV perturbed runs, start on 12:00 UTC 9 December 2003 and end on 00:00 UTC 13 December 2003 ( $84 \mathrm{~h}$ simulation time). The first twelve hours are the spin-up time and are discarded from the analysis. The PV perturbed runs start on 00:00 UTC 12 December 2003 and ends on 00:00 UTC 13 December 2003 (24 h simulation time). Perturbed forecasts last $24 \mathrm{~h}$ because their results are easier to interpret as a function of initial perturbations 


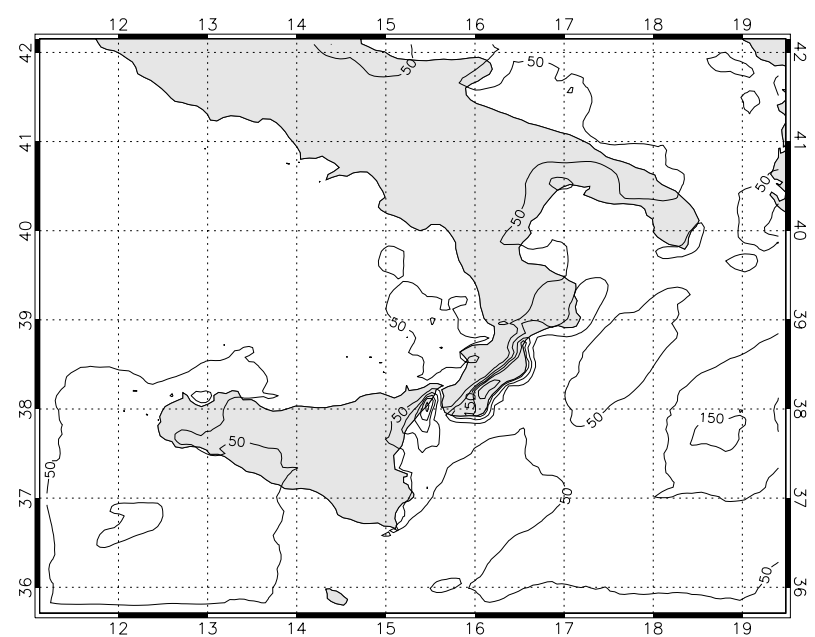

Fig. 7a. Total precipitation accumulated for the RAMS control simulation from 00:00 UTC 10 December 2003 to 00:00 UTC 13 December 2003 (same time period as Fig. 2). Contours from $50 \mathrm{~mm}$ to $250 \mathrm{~mm}$, every $50 \mathrm{~mm}$. Contour labels for $50 \mathrm{~mm}$ and $150 \mathrm{~mm}$.

compared to $84 \mathrm{~h}$ forecasts. In the latter case the perturbed and unperturbed runs can follow very different trajectory in the phase space (also due to the complexity of the Mediterranean) making their results difficult to interpret.

Usually, numerical sensitivity experiments are driven by the large scale analyzed fields, however here we emphasize the potential use of the methodology for operational purposes. Thus, we prefer to present results obtained by forcing the Limited Areas Model RAMS by the operational analysis/forecast cycle of the general circulation model rather than by the analyzed fields.

\section{Results}

\subsection{Control experiment}

The control run, simulation $f_{0}$, is able to represent the main features of the precipitation field in terms of the total amount and horizontal gradients in the north-south and west-east directions (Fig. 7a). Abundant precipitation is predicted over the Sila and Pollino mountain ranges even though they are underestimated. It is important to note that modelled rainfall often overestimates precipitation upwind of the main peaks (Federico et al., 2003a; Romero et al., 1998; Pastor et al., 2001; Mass et al., 2002) mainly for severe weather and for high horizontal resolutions as those adopted in this paper. This is clearly evident over Aspromonte where RAMS overestimates rainfall on the upwind side of the mountain peak (i.e. east and south of the main peak) and underestimates precipitation leeward. Indeed, as shown by Figs. 4 and 5 , although the flow is from the south/south-east throughout

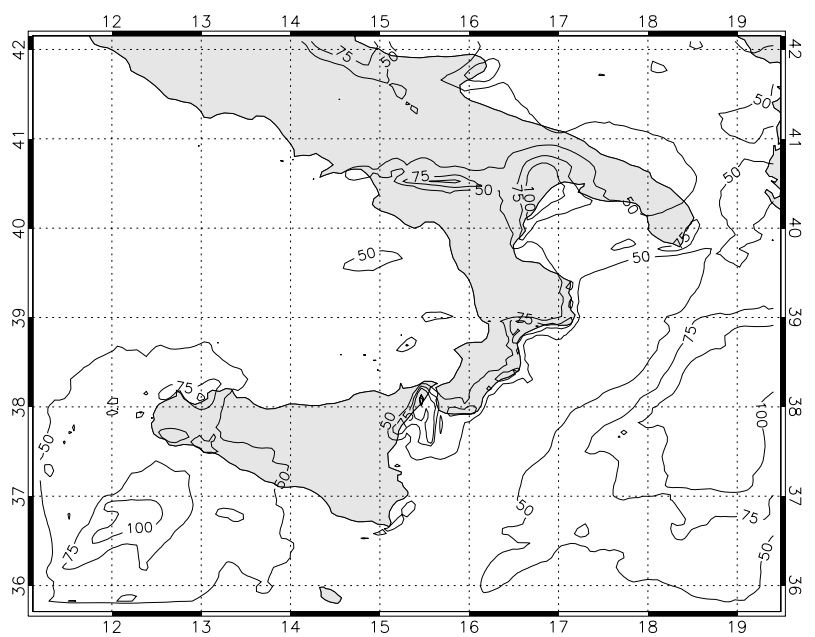

Fig. 7b. As in Fig. 7a for the simulation with no calabrian orography $\left(f_{3}\right)$. Contours from $50 \mathrm{~mm}$ to $100 \mathrm{~mm}$ every $25 \mathrm{~mm}$.

the entire event, high precipitation amounts were reported in several stations on the west side of Aspromonte, Serre, and Sila. This issue is very important to civil protection authorities because they are interested in the time and location of precipitation events larger than $50 \mathrm{~mm} /$ day in order to implement crisis management action plans.

To better evaluate model performance for this case study, deterministic scores have been computed for each simulation day and for the whole event. For objective verification we use the following methodology. First, remapping is performed from RAMS second grid to a $0.1 \circ \times 0.1 \circ$ grid following the procedure proposed by Baldwin (2000). The advantage of this method is that it can conserve precipitation to any degree of accuracy. Once remapped, the precipitation forecast is compared with rain gauge measurements. Only model grid cells containing one or more rain gauges are considered for the comparison. If more than one rain gauge is located in a grid cell, their average is considered for the comparison.

Scores are the bias (BIA), the equitable threat score (ETS), the hit rate (HR), and the false alarm rate (FAR). To compute these scores, precipitation space is divided in four mutually exclusive and exhaustive sets: Hits $(a)$ represent occasions where both rain forecasts and measurements are greater than or equal to a threshold; false alarms $(b)$ represent the number of locations where the model is above a threshold and the measurement is under the same threshold; $\operatorname{misses}(c)$ represent occasions where the measurement is above a threshold and the forecast is under the same threshold; correct no forecasts $(d)$ represent occasions where the model and measurements are both under the threshold.

Starting from the contingency table, BIA is defined as:

$\mathrm{BIA}=\frac{a+b}{a+c}$ 


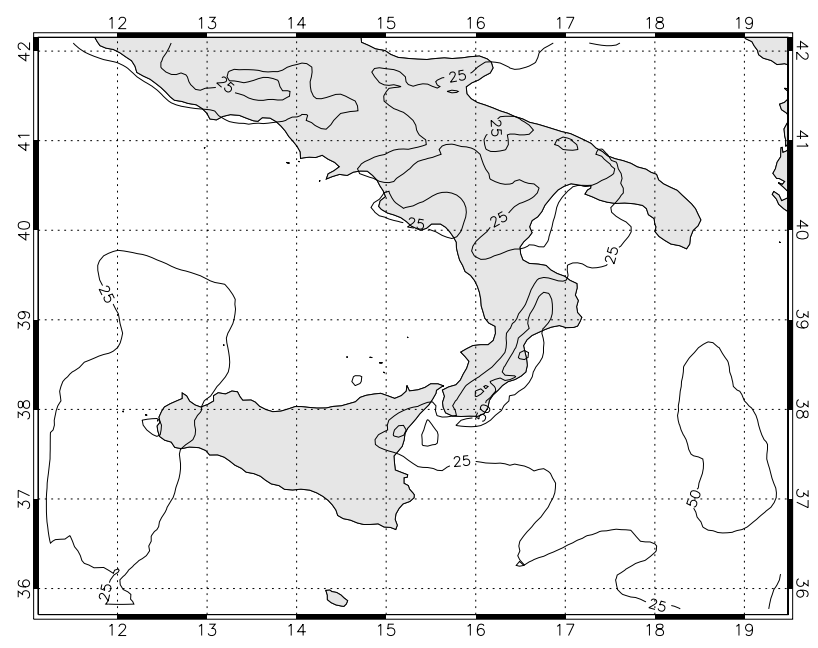

Fig. 7c. As in Fig. 7a for the simulation with no surface latent heat flux $\left(f_{2}\right)$. Contours for $25 \mathrm{~mm}$ and $50 \mathrm{~mm}$.

BIA measures if the model overestimates or underestimates precipitation frequency over an area for a selected threshold. If $\mathrm{BIA}>1$ the model overestimates the precipitation area, and if $\mathrm{BIA}<1$ the model underestimates the precipitation area. For a perfect forecast BIA is equal to 1 .

The most widely used score, ETS, is defined as:

$\mathrm{ETS}=\frac{a-a_{r}}{a+b+c-a_{r}}$

where $a_{r}$ is the expected number of correct forecasts above the threshold in a random forecast and forecast occurrence/non-occurrence is independent from observation/non-observation. It is defined as:

$a_{r}=\frac{(a+b)(a+c)}{a+b+c+d}$

For a perfect forecast ETS is equal to 1, while it is less than or equal to zero for a useless forecast.

HR and FAR are defined as:

$\operatorname{HR}=\frac{a}{(a+c)}$

$\mathrm{FAR}=\frac{b}{(b+d)}$

They represent, respectively, the proportion of events that were actually forecast and the proportion of non-events that were incorrectly forecast to occur. For a perfect forecast HR is equal to 1 and FAR is 0 .

Considering the entire event (Table 2), the model forecast performs reasonably well. In fact, the BIA score is very close to 1 for thresholds up to the $150 \mathrm{~mm}$ while there is a tendency to overestimate precipitation for $200 \mathrm{~mm}$. The good performance is also confirmed by the ETS score which is greater than 0 for all thresholds and by HR which is roughly greater than $25 \%$ for all precipitation amount and greater than $40 \%$ up to $100 \mathrm{~mm}$. False alarms are always less than HR but they

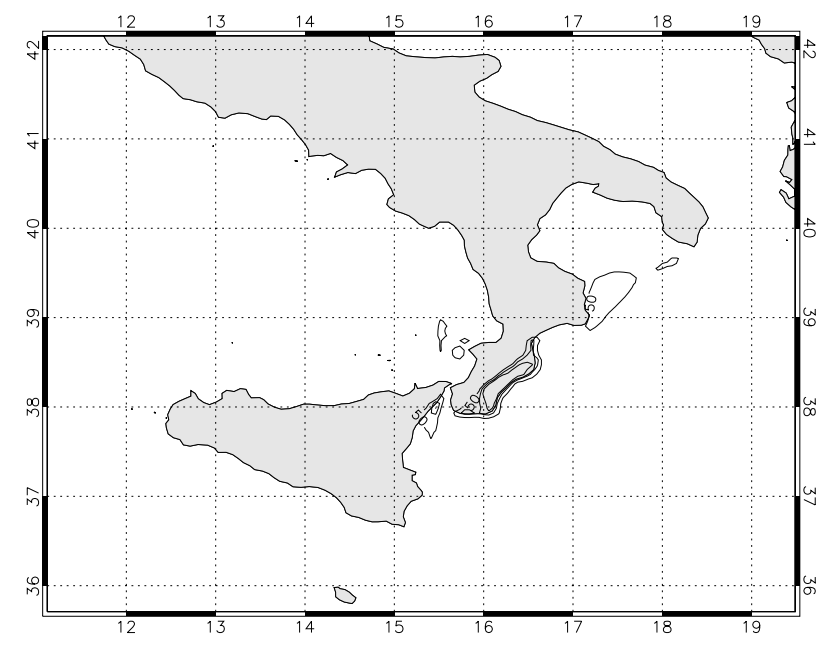

Fig. 7d. As in Fig. 7a for the combined effect $\left(f_{0}-f_{3}-f_{2}+f_{1}\right)$. Contours for $50 \mathrm{~mm} 100 \mathrm{~mm}$ and $150 \mathrm{~mm}$.

are about $30 \%$ for $50 \mathrm{~mm}$ and $100 \mathrm{~mm}$. These false alarms are mainly due to the model rainfall overestimation upwind of Aspromonte. False alarms and misses over Pollino and on the lee of Aspromonte contribute to the low value of ETS for the $200 \mathrm{~mm}$ threshold.

Score analysis for the first day shows that the model is rather humid. The BIA for 10 December is 1.57 and 5.0 for $30 \mathrm{~mm}$ and $50 \mathrm{~mm}$ thresholds and model output shows that this is due to the overestimation of the rainfall upwind of Serre and Aspromonte and to the tendency of the model to anticipate the real atmospheric behaviour. The large BIA value for $50 \mathrm{~mm}$ also determines the low performance of ETS, HR, and FAR.

Scores for the second day show that the model is capable of representing the high precipitation amounts and the extension of the rainfall field for this day because BIA is nearly 1 for all thresholds. Moreover, ETS and HR scores show that the model is also well able to represent the precipitation pattern up to the $50 \mathrm{~mm}$ threshold. For $100 \mathrm{~mm}$, a mislocation of rainfall is evident by the low value of ETS and HR while FAR is not negligible. Again, this mislocation is due to the rainfall recorded downwind of Aspromonte that is missed by the model and to the concurrent upwind forecast overestimation.

Scores for 12 December show that the model is quite able to forecast the real precipitation pattern and amount up to the $50 \mathrm{~mm}$ threshold. For higher thresholds there is a general tendency to underestimate the precipitation area. At the same time the relatively good values of ETS and HR for thresholds greater than $50 \mathrm{~mm}$ show that the forecast is able to represent part of the precipitation pattern for these thresholds, although not being able to forecast the amounts above $200 \mathrm{~mm}$. 
Table 2. Score table for 10 December (1D), 11 December (2D), 12 December (3D), and the entire event. Slashes are undefined values.

\begin{tabular}{lcccccc}
\hline Threshold (mm) & 10 & 30 & 50 & 100 & 150 & 200 \\
\hline BIA-1D & 0.90 & 1.57 & 5.0 & $/$ & $/$ & $/$ \\
ETS-1D & 0.83 & 0.18 & 0.0 & $/$ & $/$ & $/$ \\
HR-1D & 0.89 & 0.50 & 0.0 & $/$ & $/$ & $/$ \\
FAR-1D & 0.0 & 0.12 & 0.04 & $/$ & $/$ & $/$ \\
& & & & & & \\
BIA-2D & 0.77 & 0.81 & 0.90 & 0.71 & $/$ & $/$ \\
ETS-2D & 0.60 & 0.21 & 0.15 & 0.07 & $/$ & $/$ \\
HR-2D & 0.77 & 0.46 & 0.33 & 0.14 & $/$ & $/$ \\
FAR-2D & 0.0 & 0.13 & 0.09 & 0.03 & $/$ & $/$ \\
& & & & & & \\
BIA-3D & 0.79 & 0.71 & 0.74 & 0.15 & 0.12 & 0.0 \\
ETS-3D & 0.57 & 0.16 & 0.15 & 0.14 & 0.18 & 0.0 \\
HR-3D & 0.79 & 0.43 & 0.36 & 0.15 & 0.13 & 0.0 \\
FAR-3D & 0.0 & 0.17 & 0.12 & 0.0 & 0.0 & 0.0 \\
& & & & & & \\
BIA-ALL & 1.0 & 0.91 & 1.02 & 1.03 & 1.05 & 1.41 \\
ETS-ALL & 0.95 & tbf0.39 & 0.20 & 0.11 & 0.14 & 0.07 \\
HR-ALL & 0.99 & 0.79 & 0.67 & 0.42 & 0.37 & 0.27 \\
FAR-ALL & 0.00 & 0.21 & 0.34 & 0.25 & 0.11 & 0.10 \\
\hline
\end{tabular}

In conclusion, despite the rainfall simulation deficiency described above, the model is able to represent the most important features of the precipitation field over Calabria and thus the model can be used to investigate the roles of orography, surface latent heat flux, and upper level forcing that are expected to be involved in this storm.

\subsection{Sensitivity experiments}

\subsubsection{Boundary and physical factors}

To better understand the roles of orography and surface latent heat flux we discuss the precipitation fields for simulations $f_{1}, f_{2}$ and $f_{3}$ (Table 1).

Total accumulated rainfall for simulation $f_{1}$ (not reported) is less than $35 \mathrm{~mm}$ everywhere over the domain of Fig. 7 and less than $25 \mathrm{~mm}$ over Calabria. Compared to the control run (simulation $f_{0}$ ), these amounts show that synoptic forcing alone is not capable of producing the high precipitation recorded for this storm event.

Figure $7 \mathrm{~b}$ shows the total precipitation accumulated for 10-13 December for the run in which Calabria orography is flattened to $1 \mathrm{~m}$ height $\left(f_{3}\right)$ but with surface latent heat flux activated. It roughly gives the role of surface latent heat fluxes $\left(f_{3}-f_{1}\right.$, Table 1$)$ because precipitation for experiment $f_{1}$ is much less than precipitation simulated for $f_{3}$. Rainfall along the Ionian coast is confined in a short distance near the coastline because the surface roughness changes along this line and forces convergence and upward motions. The ambient flow is wet enough that air masses are able to reach their Level of Free Convection (LFC, which is as low as $950 \mathrm{hPa}$ before the initiation of convection) and precipitation occurs. The role of surface latent heat flux is not negligible, nevertheless total precipitation is largely reduced compared to the control case and suggests the important contribution of other factors to the total precipitation.

Figure $7 \mathrm{c}$ shows the total precipitation accumulated over 10-13 December for the no latent heat fluxes run $\left(f_{2}\right)$ but with the actual Calabrian orography. It roughly gives the role of the Calabrian orography $\left(f_{2}-f_{1}\right.$, Table 1$)$ because precipitation for simulation $f_{1}$ is much less than precipitation simulated for $f_{2}$.In this case the effect of topography is clear because precipitation maxima are along the main peaks, up windward. However, total precipitation is largely reduced compared to the control case and suggests the contribution of other factors to explain the precipitation amount of the case study.

Figure $7 \mathrm{~d}$ shows the synergetic effect of Calabrian orography and surface latent heat flux $\left(f_{0}-f_{3}-f_{2}+f_{1}\right.$, Table 1$)$. Humid air masses are advected from the Ionian Sea toward Calabrian east coast where they interact with the steep mountain ranges determining rainfall. This situation persisted for two days and contributed to the unusually large amounts of precipitation recorded for this event. The orography and surface latent heat flux synergetic effect gives by far the most important contribution to the total precipitation over southern Calabria compared to the previous effects analyzed, and accounts for most of the precipitation simulated in the control run $\left(f_{0}\right)$.

In conclusion, the boundary factor (orography) and the physical factor (surface latent heat flux) were fundamental mesoscale ingredients of the storm because they determined intense and abundant rainfall over Calabria, mainly by their synergic effect.

Previous results and the cyclone synoptic scale analysis (Sect. 2) suggest that the influence of the PV anomaly on the atmospheric development should be significant. We found that the key mesoscale factor is the synergic interaction between Calabrian orography and surface latent heat flux. This mesoscale factor depends on the synoptic scale cyclone development. In fact, the cyclone sea level pressure pattern ensures that air masses impinge over the steep Calabrian eastern coast after a long fetch over the sea which ensures the moisture supply (Figs. 4a and 5a) and this synoptic scale pattern is a prerequisite for the mesoscale precipitation. A perturbation in the PV field results in a different atmospheric stability and vertical motions that have an impact on the cyclone evolution at the synoptic scale. Because the key mesoscale factor of this case study strictly depends on the synoptic scale pattern, we expect that a perturbation in the PV field will have an important effect on the quantitative precipitation forecast through the modification of the synergic action of the local orography and surface latent heat fluxes.

We discuss the role of the upper level forcing in the next subsection. 


\subsubsection{Analysis of the storm PV sensitivity}

The strategy adopted to study the sensitivity of the storm to the upper level PV anomaly and to examine its predictability consists of generating different "scenarios", compatible with the analysis/forecast error, with respect to a reference run (hereafter also referred as control). In this approach we assume that the model is perfect and that the major error sources are associated with deficiencies in the knowledge of initial conditions ingested into the mesoscale model, a real problem for the Mediterranean. To generate PV perturbations we use a LEPS approach because it provides different scenarios which are compatible with current analysis/forecast errors.

LEPS methodology is detailed in the following two main points:

1. Five sets of perturbed initial and boundary conditions are generated by a hierarchical clustering technique applied to the results of a Brute Force $(\mathrm{BF})$ run performed by the RAMS model with $50 \mathrm{~km}$ horizontal resolution. The horizontal resolution of ECMWF-EPS analysis and forecast cycle is $\mathrm{T}_{\mathrm{L}} 255$, which corresponds to about $80 \mathrm{~km}$ grid-point spacing. RAMS-BF simulations enhance the horizontal resolution and are used to compute derived variables as PV or the height of the dynamic tropopause. We perform 51 runs of the RAMS model driven by the 51 global predictions of the ECMWF-EPS, then we gather those runs by the following methodology:

- We begin with 51 clusters where each RAMS-BF member belongs to one cluster.

- From $t_{0}+24 \mathrm{~h}$ to $t_{0}+84 \mathrm{~h}$, where $t_{0}$ is the initial simulation time, we calculate the space-averaged quadratic distances between all RAMS-BF members for the height of the dynamic tropopause. The space-averaged quadratic distance between RAMSBF members $k$ and $l$, at time $t$, is given by:

$\left.d(t)=\frac{1}{N} \sum_{i=1}^{N} \operatorname{hgt}_{k}(i, t)-\operatorname{hgt}_{l}(i, t)\right)^{2}$,

where $\mathrm{hgt}_{k}$ and $\mathrm{hgt}_{l}$ are the heights of the dynamic tropopause for the members $k$ and $l$, respectively, and the summation spans over all grid points inside the central Mediterranean basin $\left(5^{\prime} \mathrm{E}-20^{\prime} \mathrm{E}\right.$; $\left.35^{\prime} \mathrm{N}-45^{\prime} \mathrm{N}\right)$. The distance between members $k$ and $l$ is determined by averaging $d(t)$ over all available model outputs from $t_{0}+24 \mathrm{~h}$ to $t_{0}+84 \mathrm{~h}$.

- The two clusters with minimum distance are grouped together.

- Next, we calculate distances between different clusters by averaging distances between all cluster members.
Table 3. Result of the application of the hierarchical clustering technique.

\begin{tabular}{ccc}
\hline Cluster \# & Cluster population & Representattive member (RM) \\
\hline 1 & 26 & 6 \\
2 & 20 & 9 \\
3 & 3 & 7 \\
4 & 1 & 10 \\
5 & 1 & 44 \\
\hline
\end{tabular}

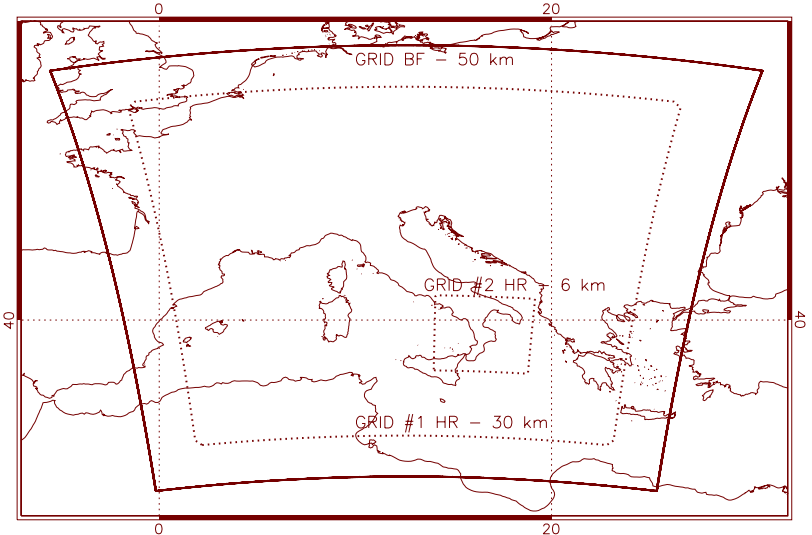

Fig. 8. Domain configurations. The outermost domain is for RAMS-BF approach with $50 \mathrm{~km}$ horizontal resolution. The inner two domains are for RAMS-LEPS configuration and their horizontal grid spacing is $30 \mathrm{~km}$ and $6 \mathrm{~km}$.

- The previous two steps are repeated until only five clusters remain.

- One representative member (RM) is selected for each of the five clusters by minimizing the ratio between the distance from its own cluster members and the distance from members belonging to other clusters.

2. For each of the five RMs, a high resolution RAMS forecast, with $6 \mathrm{~km}$ maximum horizontal resolution, is performed to resolve local scales which have a high impact on local weather and are not represented properly in the ECMWF-EPS and in the RAMS-BF because of their horizontal resolutions. For this case study the horizontal resolution of ECMWF-EPS is $\mathrm{T}_{L} 255$, which corresponds to about $80 \mathrm{~km}$ grid-point spacing. These five simulations ("scenarios") form the RAMS-LEPS.

The number of scenarios (five) was selected by trial and error considering two basic requirements: LEPS should have a proper representation of different scenarios simulated by RAMS-BF, and we need to reduce computational time to implement the method operationally. 


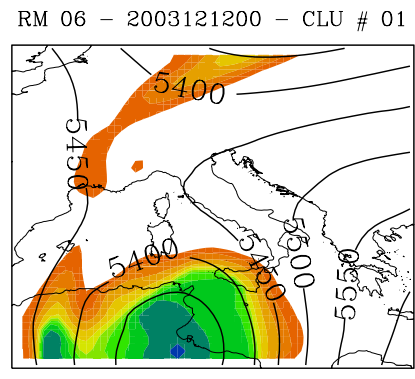

RM 07 - 2003121200 - CLU \# 03

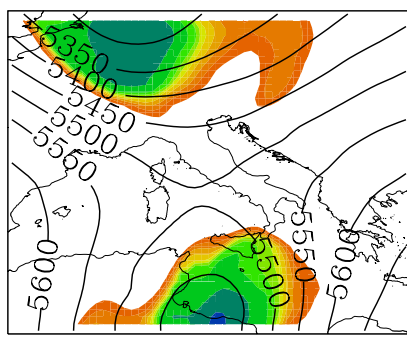

RM 44 - 2003121200 - CLU \# 05

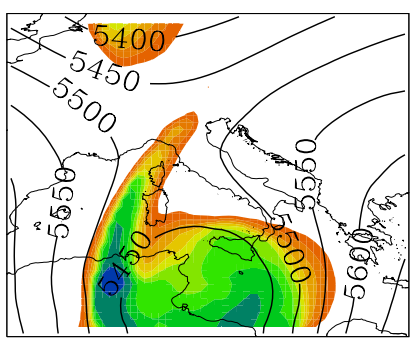

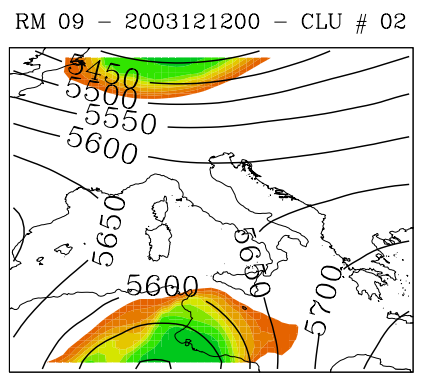

RM 10 - 2003121200 - CLU \# 04

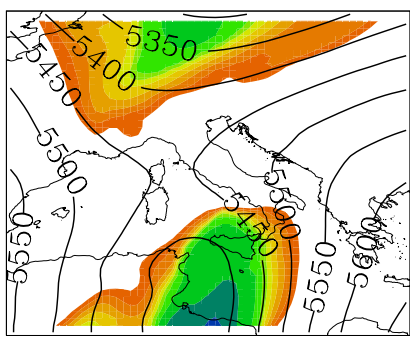

RM 00 - 2003121200 REF

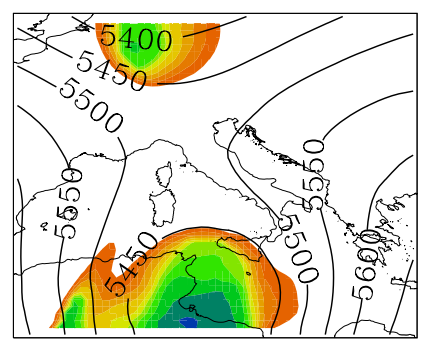

9.5

9.0

8.5

8.0

7.5

7.0

6.5

6.0

5.5

5.0

4.5

Fig. 9. Height of the dynamic tropopause (shaded colours) and $500 \mathrm{hPa}$ geopotential height (black contours) simulated on 00:00 UTC 12 December 2003 by the representative members (RM) of the five clusters (the RM number is in the upper left corner of each image). The lower right image (RM 00) is the unperturbed forecast.

Figure 8 shows the horizontal domains used by RAMS$\mathrm{BF}$ and RAMS-LEPS. The former has one grid with $50 \mathrm{~km}$ horizontal resolution and the latter has two nested grids with $30 \mathrm{~km}$ and $6 \mathrm{~km}$ horizontal resolutions (two-way nesting). Vertical levels are the same as the previously discussed simulations. This methodology was already presented in Federico et al. (2006) but, for our study, we adopt the height of the dynamic tropopause as the discriminating variable in the hierarchical clustering technique in order to focus on upper level tropospheric forcing. This height is computed for each RAMS-BF member for each grid point and for all available time outputs. Frequency of model output is $6 \mathrm{~h}$.

RAMS-BF simulations are used instead of ECMWF-EPS to increase the horizontal, and mainly the vertical resolution. ECMWF-EPS is available at standard pressure levels and we need to increase the vertical resolution to properly compute derived variables.

The application of the clustering technique for this case study gives the clusters summarized in Table 3. From now on, we associate each RAMS-BF or RAMS-LEPS member with the number of the corresponding ECMWF-EPS member whose fields are used to drive RAMS. Cluster 1 (RM 06) and cluster 2 (RM 09) account for $90 \%$ of the total RAMS-BF members. Cluster 3 (RM 07) has three members and represents $6 \%$ of the total ensemble population. Cluster 4 (RM 10) and cluster 5 (RM 44), each with one member, represent $4 \%$ of the total ensemble population.

To gain more insight into the physical interpretation of the storm evolution, we examine the height of the dynamic tropopause simulated by RMs of the five clusters and by the unperturbed forecast on 12 December 00:00 UTC (Fig. 9). This time is chosen because it is representative of RMs behaviour for 11 and 12 December. From Fig. 9 it follows that all RMs show the PV anomaly of this event even if there are differences between RMs. Hereafter RM 06 is chosen as the control forecast because it is the RM of the most populated cluster and the unperturbed forecast belongs to its cluster. 


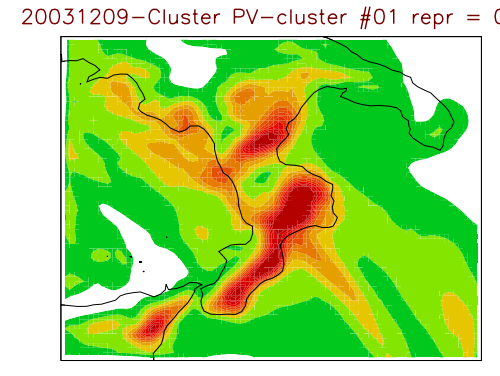

20031209-Cluster PV-cluster \#03 repr $=07$

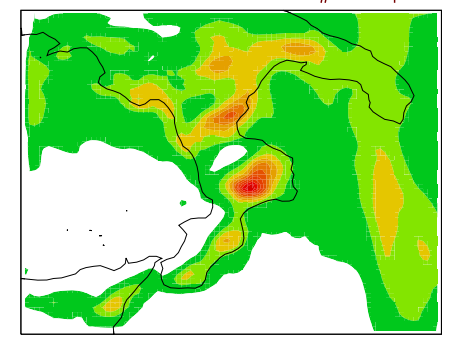

20031209-Cluster PV-cluster \#05 repr $=44$

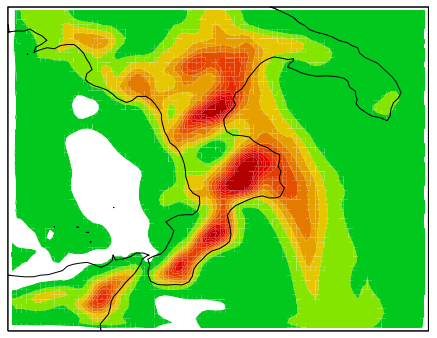

20031209-Cluster PV-cluster \#02 repr = 09

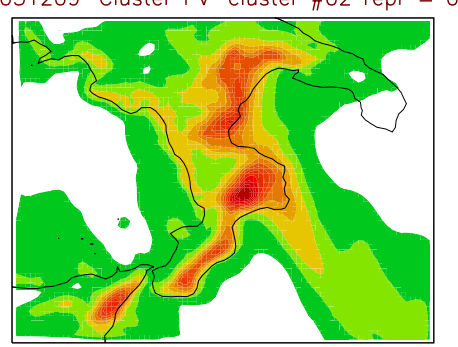

20031209-Cluster PV-cluster \#04 repr $=10$

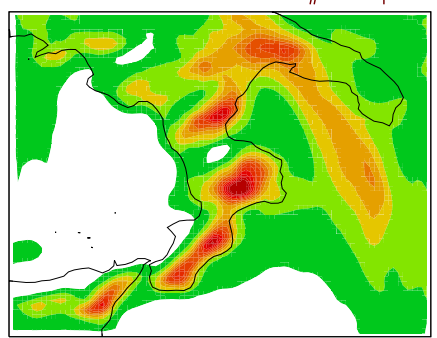

20031209-Cluster PV-cluster \#06 repr = 00

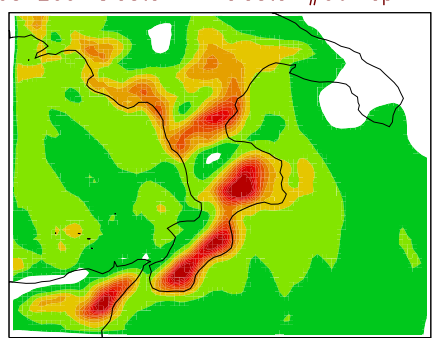

300.0

275.0

250.0

225.0

200.0

175.0

150.0

125.0

100.0

75.0

50.0

25.0

Fig. 10. Total rainfall (mm) simulated by the representative members $(\mathrm{RM})$. The RM number is in the upper right corner of each image. The lower right image (RM 00) is the unperturbed forecast.

The height of the dynamic tropopause for RM 09 (cluster 2) over Africa is higher compared to RM 06 and its pattern is slightly shifted to the east. Model output shows that the lower height of the dynamic tropopause corresponds to less intense surface winds, lower rain rate, and less accumulated rain at the end of the forecast (Fig. 10).

The RM 07 dynamic tropopause has a rather different pattern and shape compared to RM 06 . We note that the RM 07 upper level cutoff and the minimum height of the dynamic tropopause over Africa are shifted to the east. This is a consequence of a faster movement of the RM 07 cyclone from west to east with important consequences on the precipitation field (Fig. 10). As expected, RM 07 has less rainfall because the cyclone and the surface wind field are less stationary over Calabria compared to RM 06. The eastward transition speed of the cyclone is a key feature of this storm. Faster (slower) transition corresponds to a shorter (longer) interaction of surface humid air masses with the steep Calabrian orography which results in lesser (greater) rainfall over Calabria.
The RM 10 height of the dynamic tropopause pattern is similar to RM 07 and is shifted to the east compared to RM 06, however its precipitation is larger (Fig. 10) than RM 07. A closer inspection of Fig. 9 reveals that the shapes of the upper level cutoff and of the dynamic tropopause are different and extend more northward for RM 10 compared to RM 07. Model output analysis reveals that this determines more intense precipitation that lasts longer over Calabria. Similar considerations apply to RM 44.

The unperturbed forecast shows a similar pattern of the dynamic tropopause and upper level cutoff to RM 06 but it is shifted to the east. This has consequences on the accumulated rainfall for the two simulations (Fig. 10). Again, RM 06 has greater precipitation because the simulated cyclone is more stationary over Calabria and this produces greater rainfall for RM 06 compared to the unperturbed forecast.

Before we conclude this discussion on RMs, we remark that RAMS-LEPS performs well for this study and the RMs of the ensemble are able to describe the development of the cyclone and the associated rainfall pattern. Among RAMS- 
LEPS simulations, we note that only RM 07 is not able to forecast the recorded rainfall amount over southern Calabria.

The use of five scenarios gives a satisfactory physical insight to the storm evolution. Figures 9 and 10 show storm sensitivity to: (a) different values of the height of the dynamic tropopause (RM 06-RM 09); (b) cyclone progression from west to east (RM 06-RM 07); and (c) different shapes of the height of the dynamic tropopause (RM 06-RM07RM 10-RM 44). Moreover, the examination of different scenarios for other cases studies (Federico et al., 2006; Federico et al., 2007) shows that the use of five scenarios is usually a good compromise between the two basic requirements.

\subsubsection{PV sensitivity numerical experiments}

The previous analysis is the rationale for the perturbing strategy adopted in the dynamic sensitivity test discussed below, which uses the PV inversion technique summarized in Appendix A.

Our working hypothesis is that the precipitation pattern is sensitive to the mesoscale structure of the uppertropospheric PV filament. To verify this hypothesis we perform two pseudo forecasts, hereafter referred as RM 06p+ and RM06p- (perturbed RM06 forecasts plus and minus), in which two artificial initial states are generated on 00:00 UTC 12 December for the RM 06 forecast. These states serve as the initial conditions to simulate atmospheric developments during the following $24 \mathrm{~h}$. The sensitivity experiment uses the first grid of RAMS-LEPS (Fig. 8) only. RM 06 is chosen as the control state because its cluster, with 26 members, is the most populated, and the unperturbed forecast belongs to the cluster whose RM is 06 . RM 07 is chosen as the perturbing forecast because its precipitation pattern over southern Calabria is the most different from RM 06 and we are interested in investigating the influence of dynamic forcing on precipitation.

The difference between initial conditions for the RM06 and RM 06p+ simulations and the RM 06 and RM 06p- simulations is obtained by the following three steps.

- On 00:00 UTC 12 December we compute the PV complete distribution from the RM06 fields. Then, we invert this PV field, by the methodology described in Appendix A, to obtain the inverted balanced fields (i.e. geopotential, potential temperature and horizontal wind components) for the control state.

- At the same simulation time, we select a PV element from the difference between the PV fields of RM 06 and RM 07. This element is isolated by requiring that the PV difference above $500 \mathrm{hPa}$ between RM 07 and RM 06 is greater than 0.5 PVU. The volume defined by this PV element is hereafter referred as target volume. The value of $0.5 \mathrm{PVU}$ is chosen because it roughly individuates, above $500 \mathrm{hPa}$, a target volume over the Ionian Sea and the value of the PV inside this volume is expected to be important because it can influence the storm progression from west to east. Inside the target volume, the $\mathrm{PV}$ of the control state is increased (decreased) for the RM 06p+ (RM 06p-) simulation by $25 \%$ of its value giving a perturbed PV field. The value of $25 \%$ of $\mathrm{PV}$ is chosen because it gives differences in PV fields for the control and perturbed forecasts which are comparable with differences between PV values of different scenarios inside the target volume and are representative of errors that occur in the operational forecast.

- The PV perturbed field is inverted giving new balanced fields. The differences between the balanced fields obtained in this step and those obtained in the first step are added to the control state to obtain the perturbed analysis fields.

Finally we perform a new pseudo forecast starting from the perturbed analyzed fields.

Even if the methodology is overwhelmingly phenomenological and subjective, we stress that it is an efficient way to test the sensitivity of the precipitation pattern, intensity, and abundance to the upper level PV streamer position and intensity. Also, it is representative of operational forecast errors. Moreover, the methodology can be easily implemented in an operational context by involving humans in the forecasting system.

The thick line of Fig. 11a shows the area intersected by the target volume on the $300 \mathrm{hPa}$ isobaric surface. Inside this area the PV field is perturbed according to the methodology described above. The area is mainly over the Ionian Sea because of the eastward displacement of the upper level cutoff for RM 07 compared to RM 06. Figure 11a also shows the upper level cold cutoff over Tunisia.

As a consequence of the application of the PV inversion methodology for the RM 06p+ simulation (Fig. 11b), the upper level cutoff is slightly shifted to the east compared to the control forecast and it is deeper because of the increased $\mathrm{PV}$ values inside the target volume. This is also shown by the difference of the geopotential heights (shaded contours of Fig. 11b) and by the potential temperature field. The greater values of $\mathrm{PV}$ in the target volume cool the atmosphere below and warm the air above enhancing the atmospheric static stability.

Potential temperature perturbations are as large as $8-10 \mathrm{~K}$ at $300 \mathrm{hPa}$.

Conversely, the upper level cutoff for the RM 06p- forecast is shifted to the southwest compared to the control run (Fig. 11c) and is located between Libya, Tunisia, and Algeria.

Figure $12 \mathrm{a}, \mathrm{b}$, and $\mathrm{c}$ shows the geopotential height at $300 \mathrm{hPa}$ and the surface instantaneous rain rate for the RM 06, RM 06p+ and RM 06p- on 09:00 UTC 12 December, i.e. $9 \mathrm{~h}$ later the initial simulation time of the PV sensitivity experiments. Compared to state, the RM 06+ forecast cutoff (Fig. 12b) is shifted to the northeast as expected 


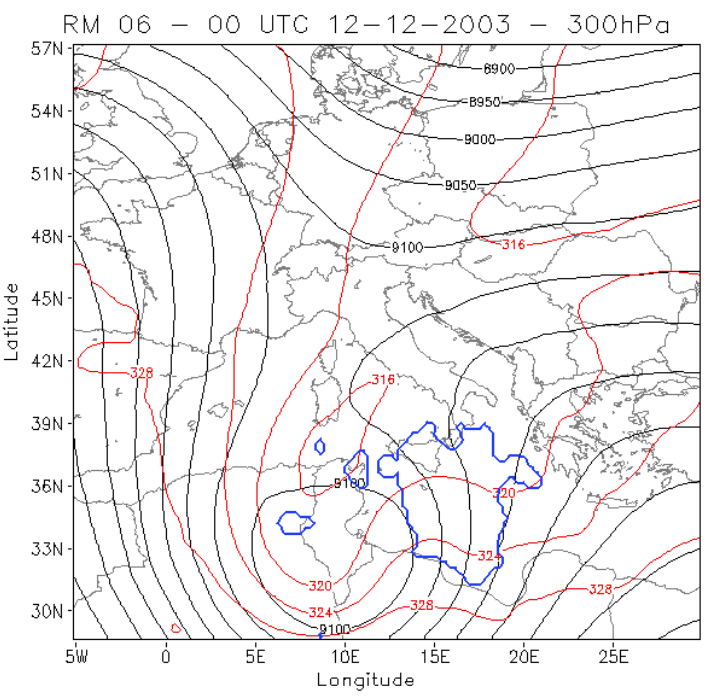

Fig. 11a. RM 06 geopotential height (m, black solid contours), potential temperature $(\mathrm{K}$, red solid contours) and the area intersected by the target volume at $300 \mathrm{hPa}$ on 00:00 UTC 12 December.

from the vorticity perturbation and resulting fields signatures added to this simulation. Rainfall surface pattern is shifted to the east: in RM 06+ precipitation is falling mainly over northeast Calabria, while in RM 06 it is still well active over southern Calabria (compare the $1 \mathrm{~mm} / \mathrm{h}$ contour of Figs. 12a and $12 \mathrm{~b}$ over southern Calabria).

Conversely, the $300 \mathrm{hPa}$ cutoff for the RM 06p - run is west of the control run cutoff (Fig. 12a) and located over the Algeria-Tunisia border (Fig. 12c). It is also higher compared to the control run, as expected from the PV perturbations and resulting fields signatures added to the RM 06p - simulation. The surface rain rate field over Calabria and Sicily also shows a southwest displacement in the RM06p- forecast compared to the control case. The $1 \mathrm{~mm} / \mathrm{h}$ contour for RM 06 lies between Calabria and Sicily while it is well over Sicily for the RM $06 \mathrm{p}-$ forecast.

These results confirm that the surface rain rate is less (more) stationary over southern Calabria for RM06p+ (RM 06-) compared to the control case. The lower (higher) stagnancy of the cyclone for 12 December determines a lesser (greater) total rainfall over Calabria as shown in Fig. 13 which reports the accumulated precipitation for RM 06 (Fig. 13a), RM 06p+ (Fig. 13b) and RM06p(Fig. 13c) for the 12 December. Rainfall is greater for RM 06 compared to RM 06p+ over almost all the domain of Fig. 13. In particular, the largest differences are in southeast Calabria and over Sicily. Rainfall over Calabria is less for RM 06p+ as a consequence of the faster eastward movement of the cyclone.

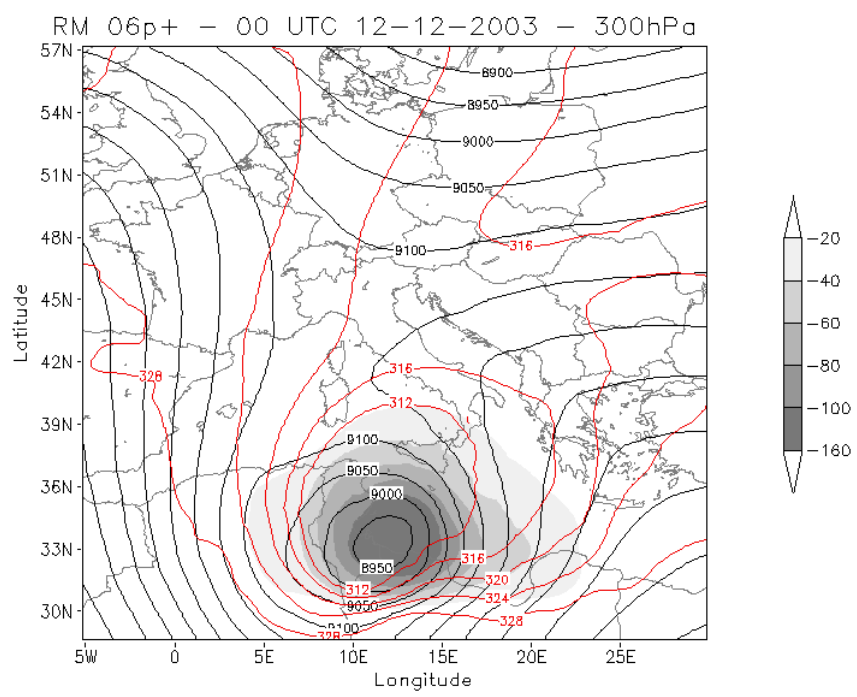

Fig. 11b. RM 06p+ geopotential height (m, black solid contours), potential temperature ( $\mathrm{K}$, red solid contours) and the difference between RM06p+ and RM06 geopotential heights (m, filled contours) at $300 \mathrm{hPa}$ on 00:00 UTC 12 December.

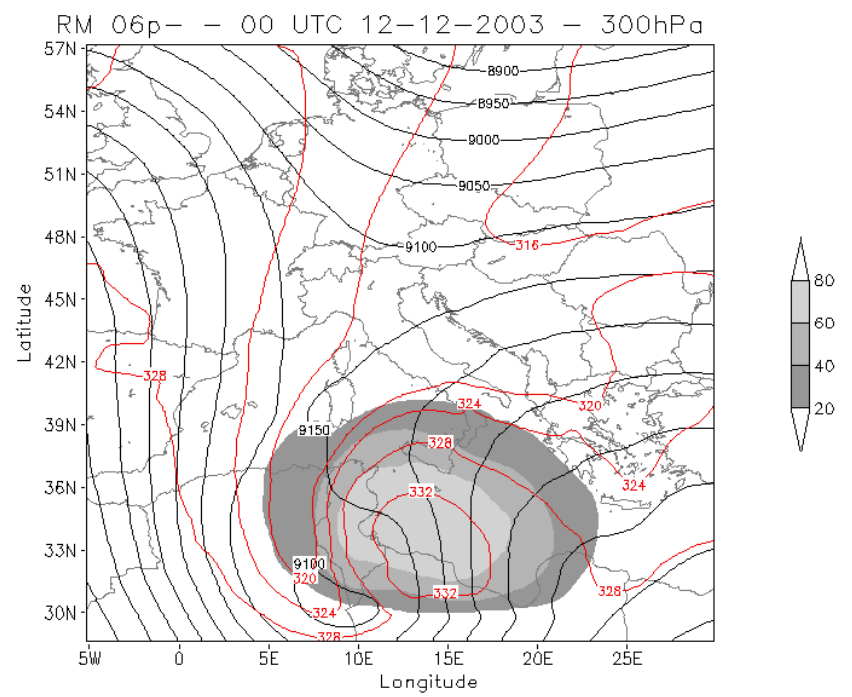

Fig. 11c. As in Fig. 11b for RM 06p-.

Conversely, RM 06p- precipitation for 12 December is greater over Calabria compared to the control simulation (Fig. 13c). Values are greater than $200 \mathrm{~mm}$ over eastern Calabria and more than $100 \mathrm{~mm}$ are simulated over all southern Calabria. Finally, we remark that differences in the precipitation fields of RM 06p+, RM 06p-, and RM06 should be even greater for higher horizontal grid resolutions. In fact, when the horizontal resolution is increased, the local topographical mesoscale features and their associated 


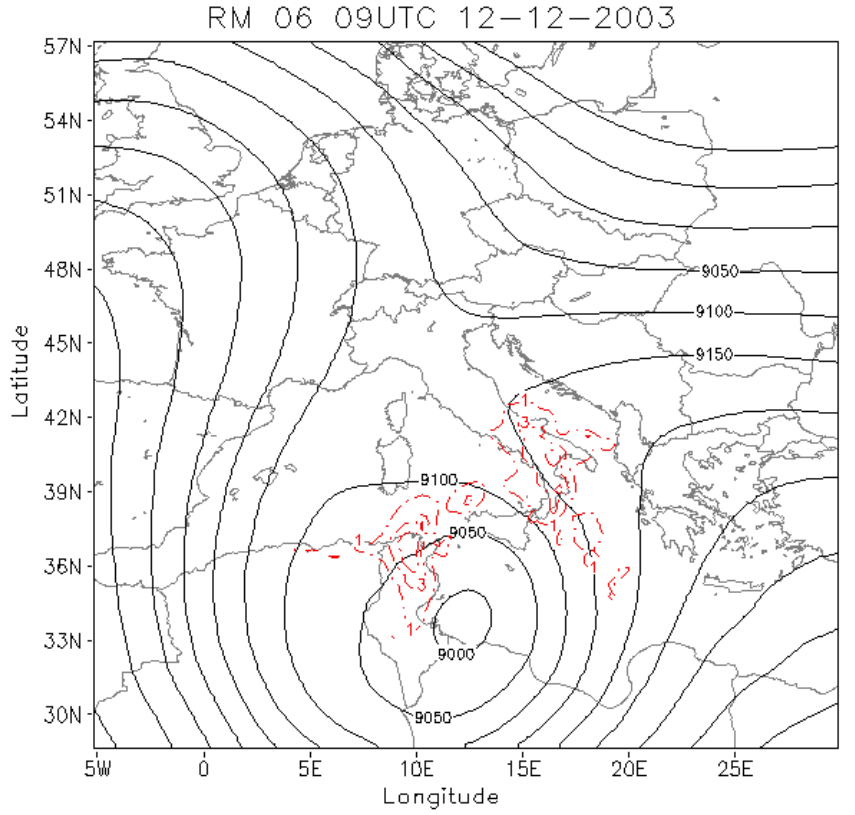

Fig. 12a. Geopotential height ( $\mathrm{m}$, solid contours) at $300 \mathrm{hPa}$ and surface instantaneous rain rate $(\mathrm{mm} / \mathrm{h}$, dot-dashed contours, contours from $1 \mathrm{~mm} / \mathrm{h}$ to $5 \mathrm{~mm} / \mathrm{h}$ every $2 \mathrm{~mm} / \mathrm{h}$ ) on 09:00 UTC $12 \mathrm{De}$ cember for the RM 06 forecast.

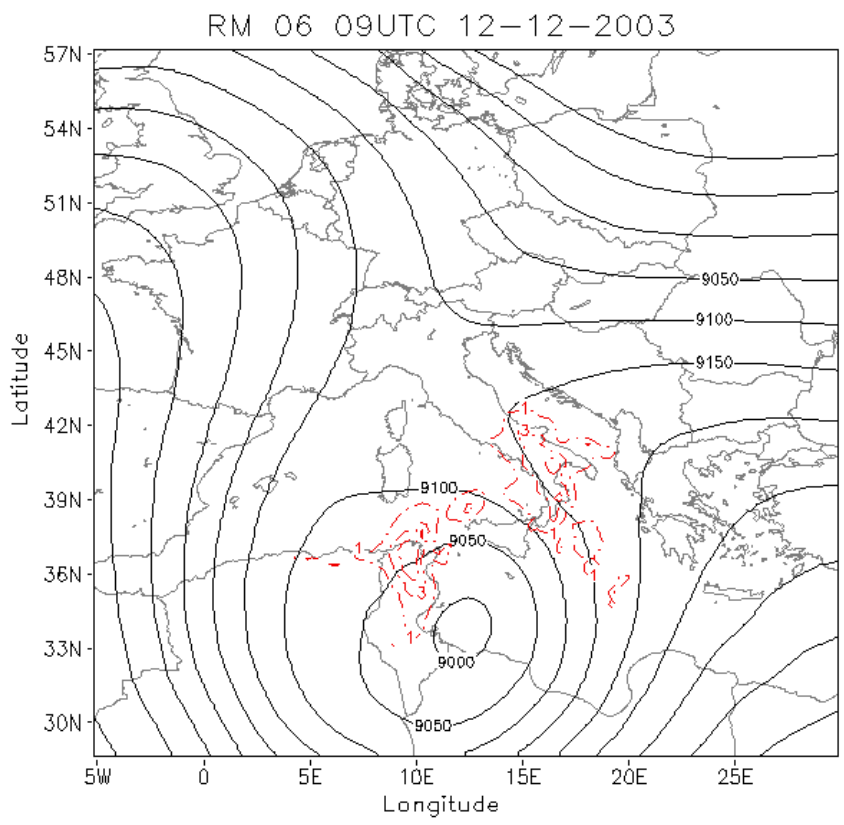

Fig. 12b. As in Fig. 12a for RM 06p+.

circulations are better resolved, producing a general increase of modelled precipitation over the upwind slopes (Mass et al., 2002). This likely enhances differences between precipi-

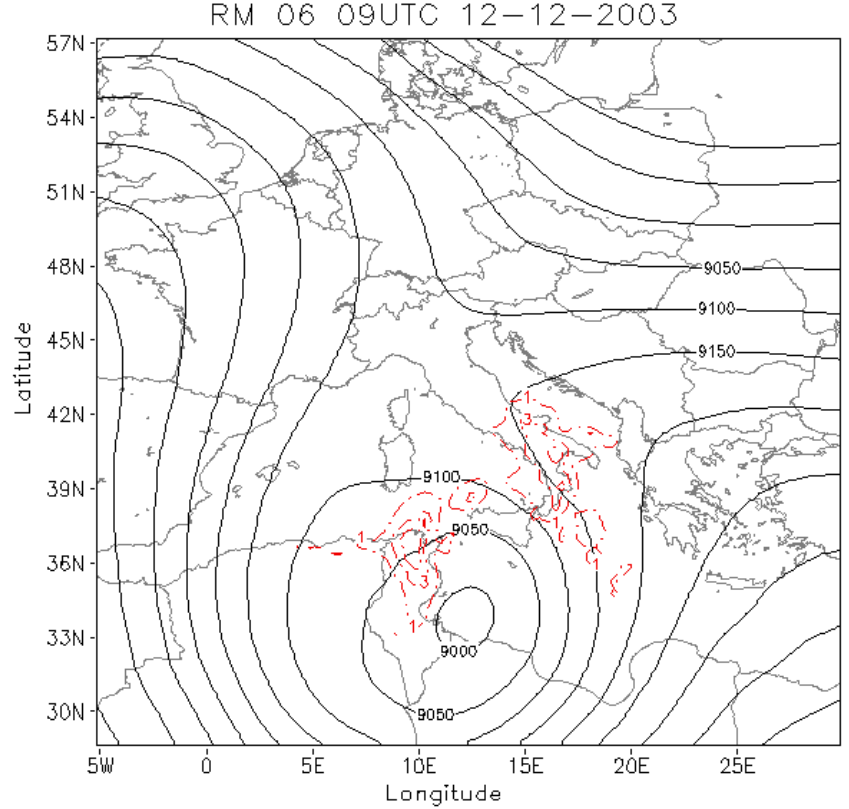

Fig. 12c. As in Fig. 12a for RM 06p-.

tation fields of different forecasts because the areas of greatest precipitation are determined by the interaction between air masses and major topographical features, so slightly different interactions can give larger differences in the precipitation field.

These results confirm that in the complex Mediterranean region, where several mountain ranges are near the sea, precipitation is quite sensitive to small changes in the cyclone pattern, stagnancy, and structure (Romero et al., 2005; Martin et al., 2007).

This sensitivity poses questions about the predictability of intense precipitation events in the central Mediterranean Sea basin. Complex physiographic features and sparse data make weather forecasting for this region a difficult task. Thus, meteorological precursors, such as the PV streamer, may need to be used in order to improve forecasts.

We speculate that the methodology reported in this subsection could be a first step in this direction for two reasons.

One, the comparison between different scenarios compatible with the analysis/forecast errors is useful to gain insight into the physical behaviour of the cyclone.

Two, when different "scenarios" are derived compatible with the analysis/forecast errors, a comparison between modelled pseudo water vapour images for cluster RMs and the corresponding METEOSAT water vapour scene can be used to evaluate the "scenarios" reliability. Preliminary results of this methodology for Calabria are presented in Federico et al. (2007).

However, we also recognize that many more case studies need to be investigated to support these issues. 


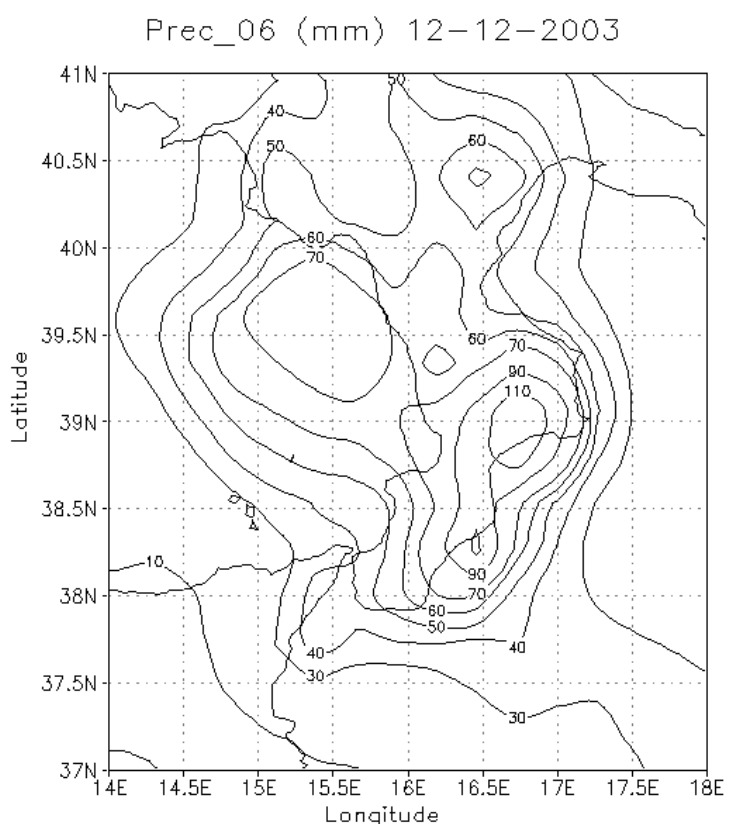

Fig. 13a. Total rainfall (mm) accumulated by the forecast RM 06 on 12 December 2003. For clarity, only a portion of the RAMS-LEPS first domain is shown.

\section{Conclusions}

In this study we use RAMS to study an intense and high impact storm that occurred over Calabria, southern Italy, on 1012 December 2003. We study the storm at the mesoscale, and evaluate the storm sensitivity to one boundary factor (Calabrian orography), one physical factor (surface latent heat flux), and one dynamic factor (PV anomaly).

The results show that mesoscale factors had a major role in this storm event. Indeed, results from the factor separation technique show that Calabrian orography and surface latent heat flux from the Mediterranean Sea contribute to the total precipitation amount mainly due to their synergetic effect and this accounts for a large part of the total precipitation that occurred over the southern part of the peninsula. This is expected by the examination of the synoptic scale forcing that advected humid and relatively warm humid air masses toward the Calabrian east coast throughout the event. Moreover, the simulation in which both physical effects are removed did not predict significant precipitation for this storm and shows that mesoscale factors were very important for this event.

Synoptic scale development of the case study is a prerequisite for the synergetic effect of mesoscale factors. In fact, it is the synoptic scale storm development which ensures that air masses move toward the steep Calabrian orography after a long fetch over the sea. Thus, the second part of the paper verifies the working hypothesis that rainfall pattern and abundance are sensitive to upper-tropospheric forcing.

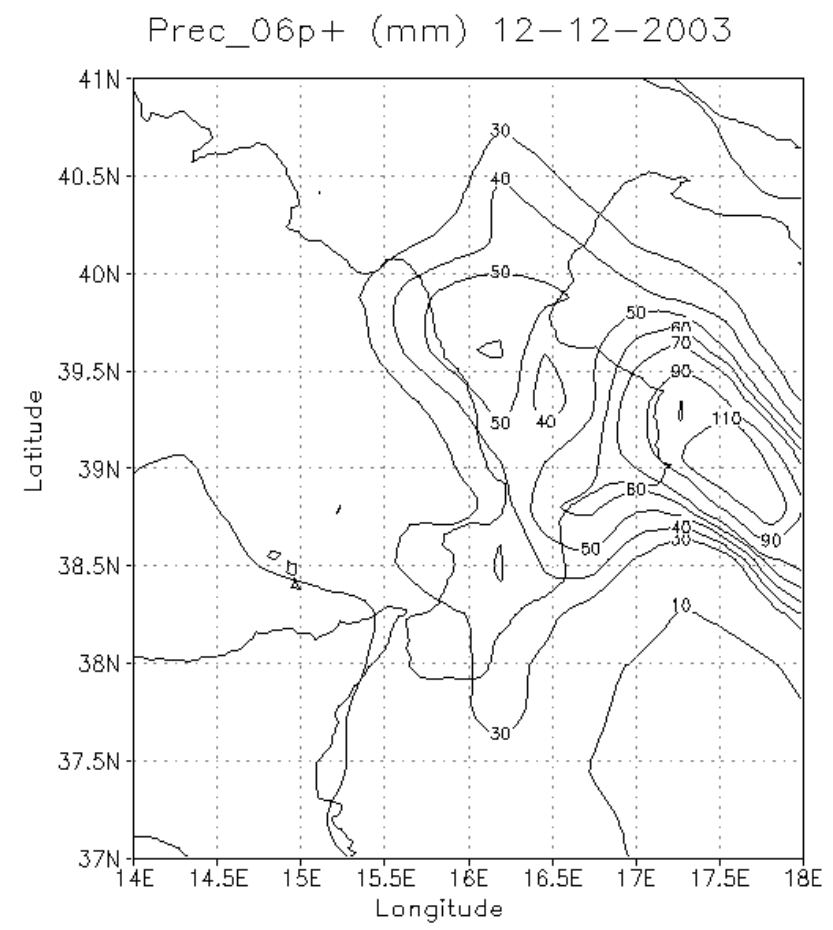

Fig. 13b. As in Fig. 13a for RM 06p+.

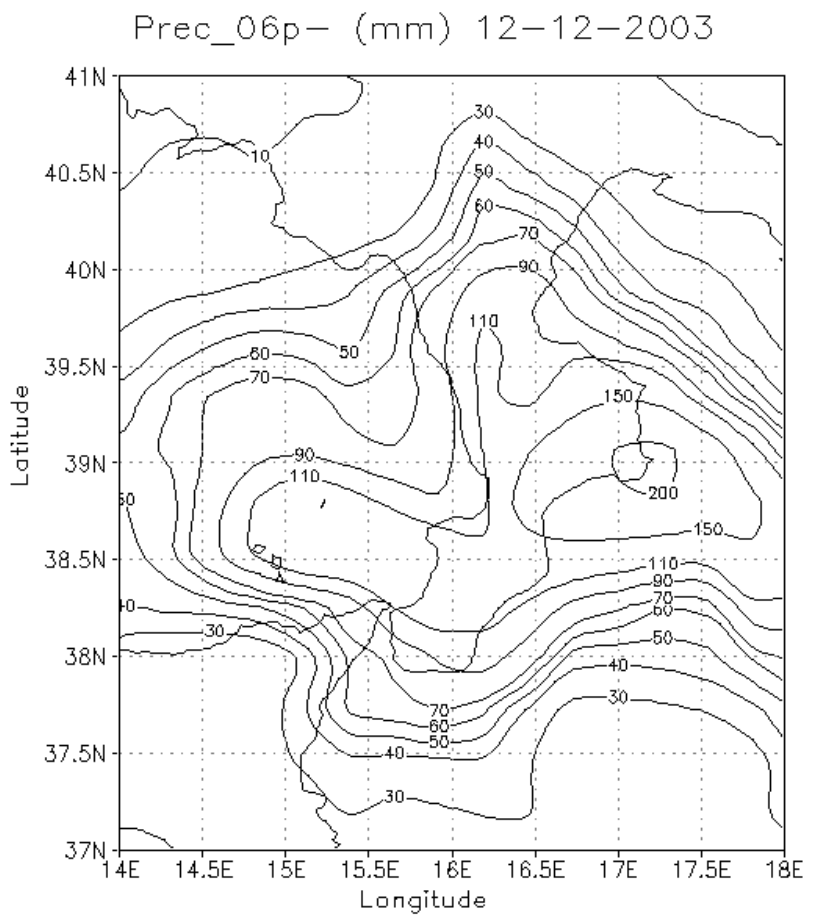

Fig. 13c. As in Fig. 13a for RM 06p-. 
PV perturbations are selected by comparing different scenarios, compatible with analysis/forecast errors, generated in a LEPS.

This analysis shows that precipitation is sensitive to the cyclone movement from west to east which is sensitive to the PV perturbations. Smaller (larger) values of upper level PV over the Ionian Sea correspond to a slower (faster) transition of the cyclone from west to east which results in a greater (lesser) precipitation over Calabria.

This point reveals the limited predictability of this kind of episode because a small change in the PV initial conditions produces a different precipitation pattern. The methodology presented in this paper, if confirmed by further investigations, suggests a possible strategy to cope with this issue.

\section{Appendix A}

The inversion technique used is illustrated in Davis and Emmanuel (1991) and was already adopted for studies in the Mediterranean basin (Fehlmann et al., 2000; Homar et al., 2002). The method consists of resolving an equation system for the geopotential $\phi$ and streamfunction $\psi$ formed by an approximate form of the Ertel PV, i.e. $q=\frac{1}{\rho} \eta \cdot \nabla \vartheta$ where $\rho$ is the air density, $\boldsymbol{\eta}$ is the absolute vorticity and $\theta$ is the potential temperature, and the nonlinear balance condition (Charney, 1955), which is very accurate for flows with large curvature. The Charney balance equation is obtained by taking the horizontal divergence of the horizontal momentum equation and decomposing the wind field into nondivergent and irrotational parts. Following Haltiner and Williams (1980), two Rossby numbers for the nondivergent and irrotational parts of the wind field are introduced given by $R_{\psi}=V_{\psi} f L$ and $R_{\chi}=V_{x} f L$, where $V_{\psi}$ and $V_{x}$ are the nondivergent and irrotational components of the velocity. Then, applying the scale analysis, the terms $O\left(R_{\psi}\right)$ are retained while the terms $O\left(R_{\chi}\right)$ and higher are neglected. The resulting equations may be written in the following form:

$$
\begin{aligned}
& q=\frac{g k \pi}{p}\left[\left(f+m^{2} \nabla^{2} \psi\right) \frac{\partial^{2} \phi}{\partial \pi^{2}}-m^{2}\left(\frac{\partial^{2} \psi}{\partial x \partial \pi} \frac{\partial^{2} \phi}{\partial x \partial \pi}+\frac{\partial^{2} \psi}{\partial y \partial \pi} \frac{\partial^{2} \phi}{\partial y \partial \pi}\right)\right] \\
& \nabla^{2} \phi=\nabla \cdot f \nabla \psi+2 m^{2}\left[\frac{\partial^{2} \psi}{\partial x^{2}} \frac{\partial^{2} \psi}{\partial y^{2}}-\left(\frac{\partial^{2} \psi}{\partial x \partial y}\right)^{2}\right]
\end{aligned}
$$

where $g$ is the acceleration of gravity, $k=R / C_{p}, p$ is the pressure, $f$ is the Coriolis parameter, $\pi=\mathrm{C}_{p}\left(p / p_{0}\right)^{k}$ is the Exner function, and $m$ is the map scale factor.

From an instantaneous distribution of PV and a boundary condition set, the three-dimensional distributions of $\phi$ and $\psi$ are obtained. Dirichlet upper and bottom boundary conditions are used in solving the system of nonlinear balanced flow following $\partial_{\pi} \phi=-\vartheta$. The three dimensional temperature is determined from the hydrostatic balance.

Acknowledgements. This work was partially funded by "Ministero dell'Università e della Ricerca Scientifica" in the framework of the projects "SAI - Messa a punto di un Sistema per l'Allerta precoce di Incendi e per la minimizzazione dei falsi allarmi” and "TAI - Tecniche Agronomiche Innovative per la valorizzazione delle produzioni ed il miglioramento della qualità ambientale". We are grateful to "Aeronautica Militare" and to ECMWF for the MARS access. We are grateful to the two referees for their useful comments and suggestions that greatly improved the quality of the paper.

Edited by: A. Mugnai

Reviewed by: two anonymous referees

\section{References}

Alpert, P., Ben-gai, T., Baharad, A., Benjamini, D., Yekutieli, D., Colacino, M., Diodato, L., Ramis, V., Romero, R., Michaelides, S., and Manes, A.: The paradoxial increase of Mediterranean extreme daily rainfall in spite of decrease in total values, Geophys. Res. Lett., 29(11), 1536, doi:10.1029/2001GL013554, 2002.

Atlas, R. and Reale, O.: Tropical cyclone-like vortices in the extratropics: Observational evidence and synoptic analysis, Wea. Forecasting, 16, 7-34, 2001.

Baldwin, M. E.: QPF verification system documentation, http://www.emc.ncep.noaa.gov/mmb/ylin/pcpverif/scores/docs/ mbdoc/pptmethod.html, last access: 9 January 2008, 2000.

Buzzi, A. and Tibaldi, S.: Cyclogenesis on the lee of the Alps: A case study, Q. J. Roy. Meteor. Soc., 104, 271-287, 1978.

Buzzi A. and Foschini, L.: Mesoscale meteorological features associated with heavy precipitation in the southern Alpine region, Meteor. Atmos. Phys, 72, 131-146, 2000.

Charney, J. G.: The use of primitive equations of motions in numerical prediction, Tellus, 7, 22-26, 1955.

Cotton, W. R., Pielke, R. A. Sr., Walko, R. L., Liston, G. E., Tremback, C. J., Jiang, H., McAnelly, R. L., Harrington, J. Y., Nicholls, M. E., Carrio, G. G., and McFadden, J. P.: RAMS 2001: Current satus and future directions, Meteor. Atm., 82, 529, 2003.

Davis, C. A., and Emmanuel, K. A.: Potential vorticity diagnosis of cyclogenesis, Mon. Wea. Rev., 119, 1397-1411, 1991.

Federico, S., Bellecci, C., and Colacino, M.: Quantitative precipitation of the Soverato flood: The role of orography and surface fluxes, Nuov. Cim. C., 26 C, 7-22, 2003a.

Federico, S., Bellecci, C., and Colacino, M.: Numerical simulation of Crotone flood: storm evolution, Nuov. Cim. C., 26 C, 357371, 2003b.

Federico, S., Avolio, E., Bellecci, C., Colacino, M., and Walko, R. L.: Application of the LEPS technique for Quantitative Precipitation Forecasting (QPF) in southern Italy: A preliminary study, Nonlin. Processes Geophys., 13, 53-66, 2006, http://www.nonlin-processes-geophys.net/13/53/2006/.

Federico, S., Avolio, E., Bellecci, C., Lavagnini, A., and Walko, R. L.: Predictability of intense rain storms in the Central Mediterranean basin: sensitivity to upper-level forcing, Adv. Geosci., 12, 5-18, 2007, http://www.adv-geosci.net/12/5/2007/.

Fehlmann, R. and Davies, H. C.: Role of salient potential vorticity elements in an event of frontal-wave cyclogenesis, Q. J. Roy. Meteor. Soc., 125, 1801-1824, 1999. 
Fehlmann, R., Quadri, C., and Davies, H. C.: An Alpine rainstorm: Sensitivity to the mesoscale upper level structure, Wea. Forecasting, 15, 4-28, 2000.

Haltiner, G. J. and Williams, R. T.: Numerical prediction and dynamic meteorology, 2nd Edition, Johm Wiley \& Sons, New York, 1980.

Homar, V., Ramis, C., and Alonso, S.: A deep cyclone of African origin over the Western Mediterranean: diagnosis and numerical simulation, Ann. Geophys., 20, 93-106, 2001, http://www.ann-geophys.net/20/93/2001/.

Homar, V., Romero R., Ramis, C., and Alonso, S.: Numerical study of the October 2000 torrential precipitation over eastern Spain: analysis of the synoptic-scale stationarity, Ann. Geophys., 20, 2047-2066, 2002,

http://www.ann-geophys.net/20/2047/2002/.

Hoskins, B. J., McIntyre, M. E., and Robertson, A. W.: On the use and significance of isentropic potential vorticity maps, Q. J. Roy. Meteor. Soc., 111, 877-946, 1985.

Jansa, A., Radinovic, D., Alpert, P., Genoves, A., Campins, J., and Picornell, M. A.: Mediterranean cyclones: Subject of a WMO Project, Internat. Symposium on the Life Cycle of Extratropical Cyclones, Bergen, Vol. II, 26-31, 1994.

Krichak, S. O., Alpert, P., and Melina, D.: The role of atmospheric processes associated with hurricane Olga in the December 2001 floods in Israel, J. Hydrometeor., 5, 1259-1270, 2004.

Krichak, S. O., Alpert, P., and Dayan, M.: A southeastern Mediterranean PV streamer and its role in December 2001 case with torrential rains in Israel, Nat. Hazards Earth Syst. Sci., 7, 1-12, 2007 , http://www.nat-hazards-earth-syst-sci.net/7/1/2007/.

Martin, A., Romero, R., Homar, V., De Luque, A., Alonso, S., Rigo, T., and Llasat, C.: Sensitivities of a flash flood event over Catalonia: a numerial analysis, Mon. Wea. Rev., 135, 651-669, 2007.

Mass, C. F., Ovens, D., Westrick, K., and Colle, B. A.: Does increasing horizontal resolution produce more skilful forecasts?, B. Am. Meteorol. Soc., 83, 407-430, 2002.

Molinari, J. and Corsetti, T.: Incorporation of cloud-scale and mesoscale down-drafts into a cumulus parametrization: results of one and three-dimensional integrations, Mon. Wea. Rev., 113, 485-501, 1985.
Pastor, F., Estrela, M. J., Peñarrocha, D., and Millán, M. M.: Torrential Rains on the Spanish Mediterranean Coast: Modeling the Effects of the Sea Surface Temperature, J. Appl. Met., 40, 1180 1195, 2001.

Pielke, R. A., Cotton, W. R., Walko, R. L., Tremback, C. J., Lyons, W. A., Grasso, L. D., Nicholls, M. E., Murran, M. D., Wesley, D. A., Lee, T. H., and Copeland, J. H.: A comprehensive meteorological modelling system-RAMS, Meteorol. Atmos. Phys., 49, 69-91, 1992.

Romero, R., Ramis, C., Alonso, S., Doswell III, C. A., and Stensrud, D. J.: Mesoscale Model Simulations of Three Heavy Precipitation Events in the Western Mediterranean Region, Mon. Wea. Rev., 126, 1859-1881, 1998.

Romero, R., Martín, A. , Homar, V., Alonso, S., and Ramis, C.: Predictability of prototype flash flood events in the Western Mediterranean under uncertainties of the precursor upper-level disturbance: The HYDROPTIMET case study, Nat. Hazards Earth Syst. Sci., 5, 505-525, 2005, http://www.nat-hazards-earth-syst-sci.net/5/505/2005/.

Santurette, P. and Georgiev, C. G.: Weather Analysis and Forecasting, Elsevier Academic Press, 179 pp., 2005.

Siccardi, F.: Rainstorm hazards and related disasters in the western Mediterranean region, Remote Sens. Rev., 14, 5-21, 1996.

Stein, U. and Alpert, P.: Factor Separation in Numerical Simulations, J. Atmos. Sci., 50, 2107-2115, 1993.

Turato, B., Reale, O. and Siccardi, F.: Water Vapor Sources of the October 2000 Piedmont Flood, J. Hydrometeor., 5, 693-712, 2004.

Walko, R. L., Band, L. E., Baron, J., Kittel, T. G., Lammers, R., Lee, T. J., Ojima, D., Pielke, R. A. Sr., Taylor, C., Tague, C., Tremback, C. J., and Vidale, P. L.: Coupled Atmosphere-BiosphereHydrology Models for environmental prediction, J. Appl. Met., 39, 931-944, 2000. 